(2) Open Access Full Text Article

\title{
Design and development of Nrf2 modulators for cancer chemoprevention and therapy: a review
}

This article was published in the following Dove Press journal:

Drug Design, Development and Therapy

\section{Matej Sova' \\ Luciano Saso ${ }^{2}$}

'Faculty of Pharmacy, University of Ljubljana, Ljubljana, Slovenia; ${ }^{2}$ Department of Physiology and Pharmacology "Vittorio Erspamer", Sapienza University, Rome, Italy
Correspondence: Matej Sova Faculty of Pharmacy, University of Ljubljana, Aškerčeva 7, 1000 Ljubljana, Slovenia

Tel +386 | 4769577

$\mathrm{Fax}+386$ I 425803 ।

Email matej.sova@ffa.uni-lj.si

\begin{abstract}
A major cell defense mechanism against oxidative and xenobiotic stress is mediated by the Nrf2/Keap1 signaling pathway. The Nrf2/Keap1 pathway regulates gene expression of many cytoprotective and detoxifying enzymes, thus playing a pivotal role in maintaining redox cellular homeostasis. Many diseases including cancer have been closely related to impaired Nrf2 activity. Targeting Nrf2 and modulating its activity represents a novel modern strategy for cancer chemoprevention and therapy. In this review, different design strategies used for the development of Nrf2 modulators are described in detail. Moreover, the main focus is on important and recently developed Nrf2 activators and inhibitors, their in vitro and in vivo studies, and their potential use as chemopreventive agents and/or cancer therapeutics.
\end{abstract}

Keywords: Nrf2, oxidative stress, signaling pathway, cytoprotective, chemopreventive agents, cancer therapeutics

\section{Introduction}

Cancer presents a major public health problem around the world, and it is currently the second leading cause of death in developed countries. ${ }^{1}$ Tens of millions of people are diagnosed with different types of cancer each year, and more than half eventually die because of cancer progression. ${ }^{2}$ Uncontrolled proliferation, resistance to apoptosis, metastasis, and escape from immune surveillance are the main features of tumor cells. ${ }^{3}$ Furthermore, a high level of oxidative stress, which is exerted by ROS and/or RNS, is also one of the main characteristics of cancer cells. ${ }^{4}$ In humans, complex defensive machinery acts to defend against the attacks of ROS and RNS, which are regularly generated in the human body from cellular metabolism and environmental exposure. ${ }^{5,6}$ One of the main pathways responsible for cell defense against oxidative and xenobiotic stress is the Nrf2/Keap1 signaling pathway. ${ }^{7}$

The Nrf2/Keap1 pathway is an inherited defense system offering protection against a wide spectrum of stressors, including oxidative and chemical stress. ${ }^{8} \mathrm{Nrf} 2$ belongs to the cap " $n$ " collar subfamily of basic region leucine zipper transcription factors and plays an important role in the transcriptional stimulation of $\beta$-globin genes. ${ }^{9}$ Under normal physiological conditions, Nrf2 is bound to cysteine-rich protein Keap1, a repressor protein that binds to $\mathrm{Nrf} 2$, and promotes its ubiquitination via Cul3-based E3 ligase and degradation by the ubiquitin-proteasome pathway, ${ }^{10,11}$ whereas upon exposure to oxidative and xenobiotic stress, reactive cysteine residues of Keap1 become modified. Nrf2 is thus released from Keap1 and further on translocated into nucleus where it triggers cytoprotection of the cell by binding together with small Maf proteins to the ARE in the regulatory regions of target genes (Figure 1). ${ }^{10,11} \mathrm{Nrf} 2$, which was first identified in humans in $1994,{ }^{12}$ is a 605 -amino-acid-long protein composed of 

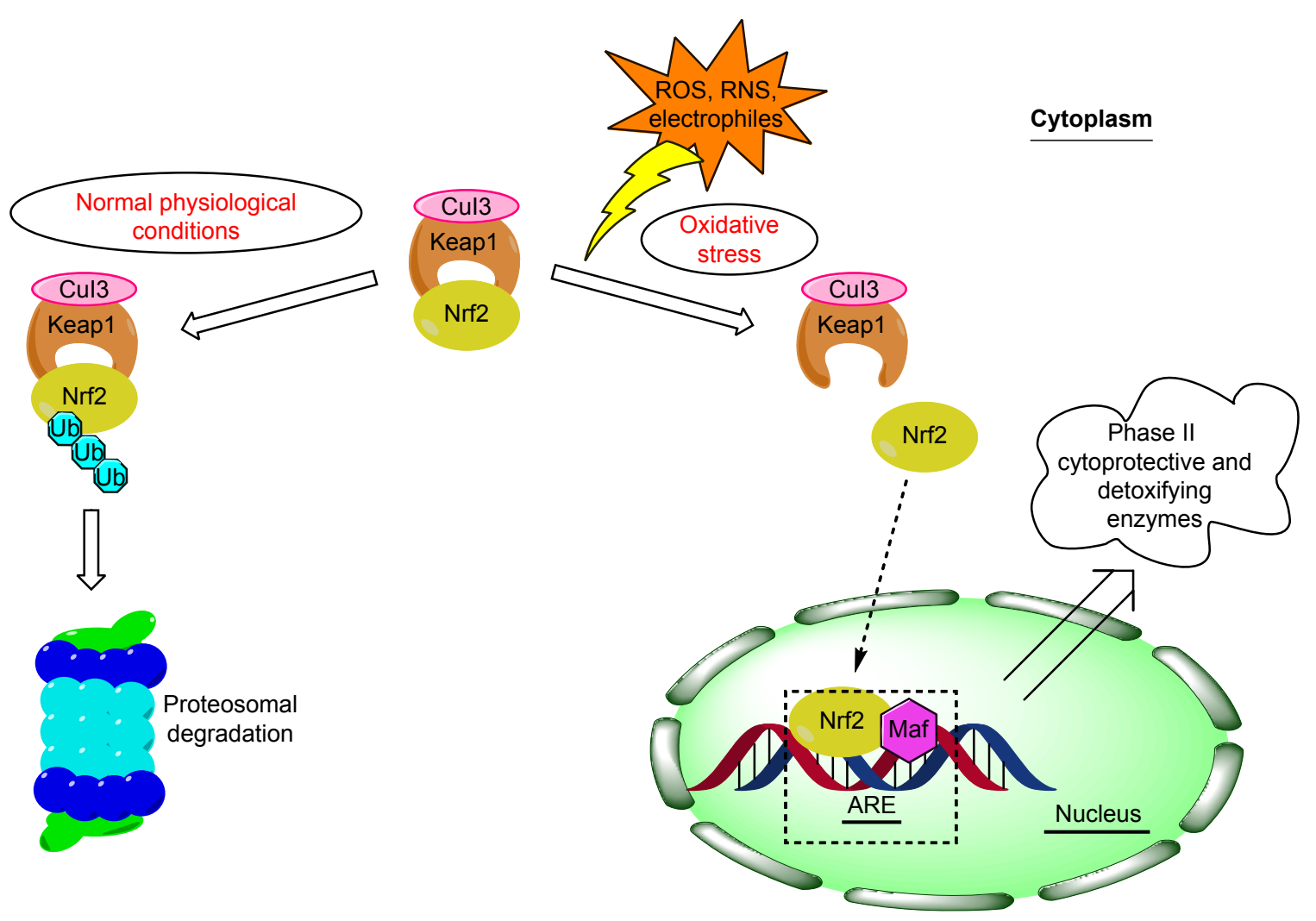

Figure I Schematic overview of the Nrf2/Keapl signaling pathway in homeostatic and stress conditions.

Abbreviations: ARE, antioxidant response element; Cul3, Cullin-3; Maf, musculoaponeurotic fibrosarcoma; RNS, reactive nitrogen species; ROS, reactive oxygen species; Ub, ubiquitination.

seven highly conserved regions, which were named as Neh domains. Four years later, a negative regulator of Nrf2 was discovered and named as Keap1 due to structural similarity to a Drosophila actin-binding protein called Kelch. ${ }^{13,14}$ Keap1 is a 624-amino-acid-long cytoplasmic protein which contains five domains: the amino terminal region domain, BTB domain involved in homodimerization of Keap1, the intervening region domain important for functional interaction of Keap 1 with Nrf2, the double-glycin repeat (also called Kelch domain), and C-terminal region domain, both responsible for mediating the binding of Keap 1 to the Neh2 domain of Nrf2. ${ }^{10,15-17}$ Two conserved motifs important for Keap1 binding were identified within the Neh2 domain of Nrf2: the weaker binding DLG motif essential for ubiquitination and degradation of Nrf2, and stronger binding ETGE motif needed for interaction with Keap $1 .{ }^{17}$

The main interactions between Nrf2 and Keap1 could be seen from two published crystal structures (Figure 2): human Kelch domain bound to the 16mer peptide (PDB ID: 2FLU) ${ }^{18}$ and Nrf2-derived peptide consisting of residues 77-82 of human Nrf2 cyclized by an additional glycine residue (cycloGD ${ }_{77}$ EETGE $_{82}$, PDB ID: 3ZGC). ${ }^{19}$ The Nrf2-derived peptides adopt the $\beta$-turn conformation that binds into the shallow pocket on the top face of the Kelch domain with a buried surface area of $420 \AA^{2}{ }^{18}$ The entrance of the pocket is surrounded by hydrophobic residues Tyr572, Tyr525, Phe478, and Tyr334, which forms hydrogen bond with NH of Glu82. ${ }^{18}$ The most important contacts are between arginine residues from the Kelch domain of Keap1 and glutamate residues of the Nrf2-derived peptide. Keap1 residues Arg415, Arg483, and Ser508 form hydrogen bonds with Glu79 from the ETGE motif of Nrf2, whereas Keap1 residues Ser363, Arg380, and Asn382 are bound to Glu82 of Nrf2 with four additional hydrogen bonds. Keap1 residues Gln530 and Ser602 also form hydrogen bonds with peptide residues Glu78 and Thr80, respectively. ${ }^{18,20}$

The Nrf2/Keap1 pathway regulates the gene expression of many cytoprotective and detoxifying enzymes, thus playing an important role in maintaining redox cellular homeostasis. ${ }^{21}$ Indeed, the target genes of Nrf2 have been implicated in the antioxidant activity via activation and production of different proteins and enzymes, the synthesis and conjugation of GSH, metabolizing enzymes of xenobiotics, drug transport, and the activity of metabolic genes and transcription factors. ${ }^{22,23}$ Therefore, it is evident that modulating the activity of Nrf2 could represent a novel modern therapeutic strategy. 


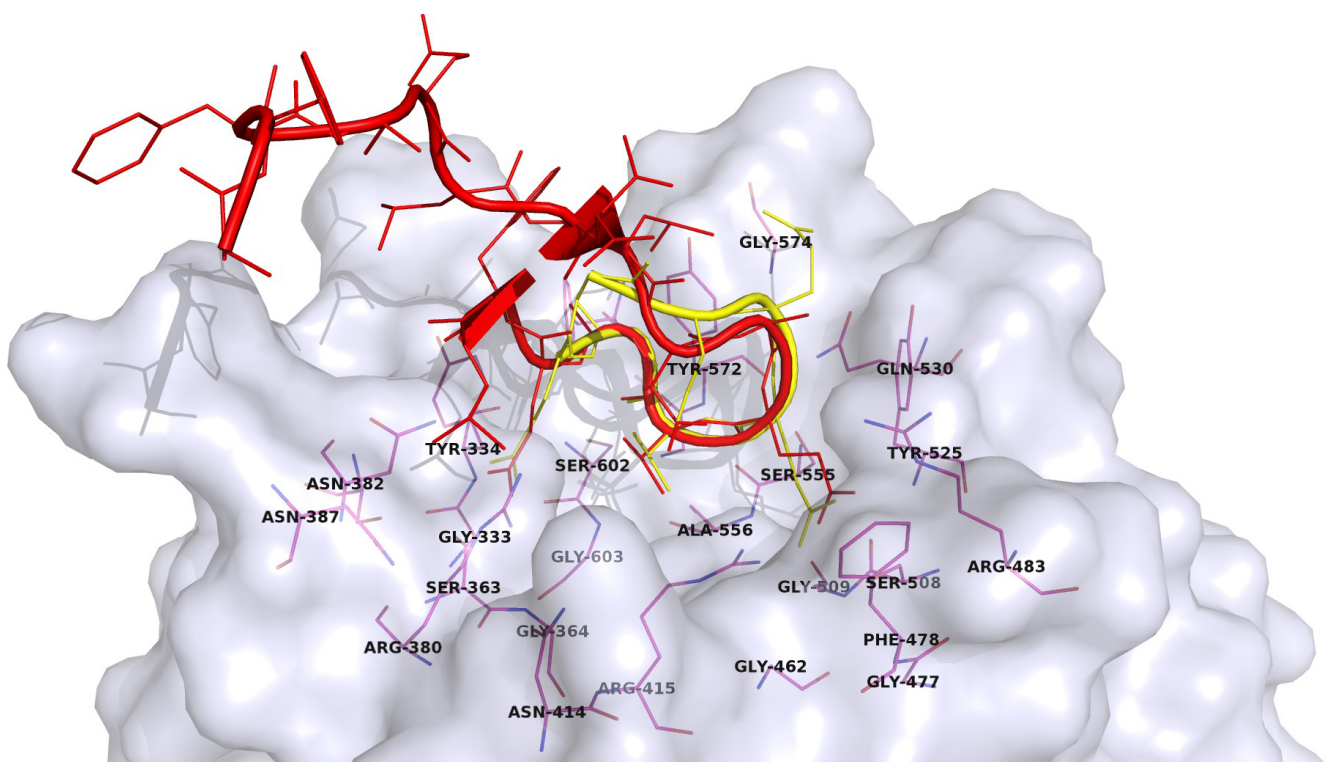

Figure 2 A surface presentation of the Kelch domain (gray) with two bound peptides from crystal structures: 2FLU (red) ${ }^{18}$ and $3 Z$ GC (yellow). ${ }^{19}$

Moreover, designed Nrf2 activators and also inhibitors could be of use for the treatment of many diseases, especially those that involve oxidative stress, such as cancer. A number of reviews ${ }^{16,22-34}$ have covered the Keap1/Nrf2/ARE pathway as a potential preventive and therapeutic anticancer strategy.

Herein, we present the role of Nrf2 in cancer and different strategies that have been used for the design and development of Nrf2 modulators. Moreover, we provide an update on the most important and recently developed Nrf2 modulators (activators and inhibitors), their in vitro and in vivo studies, and their potential use as chemopreventive agents and/or cancer therapeutics.

\section{The connection between cancer and the Nrf2 pathway}

Three main distinct stages of the carcinogenesis process have been defined: initiation, promotion, and progression. ${ }^{35,36}$ Several in-depth reviews $s^{4,36-38}$ have covered the connection between oxidative stress and cancer explaining the critical role of oxidative stress during the initiation and progression of cancer. It is now evident that the level and duration of the oxidative stress exposure may contribute to tumor formation (at low-to-moderate levels of ROS by inducing the mutations of genomic DNA or stimulation of cell proliferation) or severe cellular damage and cell death (at high levels of ROS by excessive DNA damage)., ${ }^{4} 39$ Since the Nrf2/Keap1 signaling pathway is the key player in regulating oxidative stress, ${ }^{25,40}$ the connection between Nrf2 and cancer is inevitable. However, the dual role of Nrf2 in $\operatorname{cancer}^{26,27}$ has to be considered when designing novel Nrf2 modulators. Since the discovery of Nrf2, many studies have shown its protective role against cancer. Because of its importance in maintaining redox cellular homeostasis, Nrf2 has been generally considered as a cytoprotective transcription factor, and furthermore, a tumor suppressor. Indeed, at lower homeostatic levels, Nrf2 is able to eliminate ROS, carcinogens, and many other DNA-damaging agents, which lead to the inhibition of tumor initiation and cancer metastasis. ${ }^{23}$ On the other hand, there are many reviews in the last few years suggesting that the activation of Nrf2/Keap1 signaling pathway is not favorable in all cancer types and stages. ${ }^{16,23,27}$ Indeed, the increased Nrf2 activity in many cancer types assists malignant cells in defending against excessive oxidative stress, chemotherapeutic agents, and radiotherapy. The Nrf2 activation in cancer cells can occur due to disrupted binding of Keap1 to Nrf2 as a consequence of somatic mutations within the Keapl and Nrf2 genes, epigenetic silencing of Keapl gene, accumulation of Keap1-interacting proteins, and cysteine modification of Keap1 by metabolites (Table 1). ${ }^{10,16,34,41-56}$ In addition, Nrf2 assists in avoiding apoptosis via activation of cytoprotective genes that contribute to enhanced cell proliferation. ${ }^{23,27}$ Therefore, when deciding to design modulators of the Nrf2/ Keap1 signaling pathway, both aspects have to be considered to achieve the desired positive effect in cancer cells. However, due to the oncogenic role of Nrf2 at the early stages of cancer development, the design of inhibitors of Nrf2/ Keap1 signaling pathway seems to be the right strategy at the moment. 
Table I The origin and mechanisms of the Nrf2 activation in different cancer types

\begin{tabular}{|c|c|c|c|}
\hline Mechanisms of Nrf2 activation & Type of cancer & Change/cause (representative examples) & Reference \\
\hline \multirow[t]{14}{*}{ Somatic mutations in Keap I } & Lung, AD & G430C, R4I5G & $4 I, 42$ \\
\hline & & E244K, E242K, W59IL & 43 \\
\hline & Lung, NSCC & G333C & 44 \\
\hline & Lung, SQ & S45F, V42A, R320 & 43 \\
\hline & Gastric, AD & F280L, Q82H, S233N & 43 \\
\hline & Colorectal, AD & T330I, V660M, R234W & 43 \\
\hline & $\mathrm{HCC}$ & D236Y, L342M, NI83S & 43 \\
\hline & Breast cancer & D256G & 43 \\
\hline & & $\mathrm{C} 23 \mathrm{Y}$ & 45 \\
\hline & Prostate, AD & D357N & 43 \\
\hline & & $\mathrm{Y} 255 \mathrm{H}, \mathrm{T} 3 \mathrm{I} 4 \mathrm{M}$ & 46 \\
\hline & Gallbladder, AD & G379D, S338L & 47 \\
\hline & Liver, CCC & W554X, C249Y & 47 \\
\hline & Epithelial ovarian cancer, CC & FI07L, AI59T and AI88V, E6IIK, P4I2S & 48 \\
\hline \multirow[t]{12}{*}{ Somatic mutations in $\mathrm{Nrf2}$} & Lung, AD & E79Q & 49 \\
\hline & Lung, NSCC & D77V, E79K & 49 \\
\hline & Lung, SQ & E79K, T80R, E82G, etc & 49,41 \\
\hline & & D77A, E79K or Q, G8ID, E82Q, etc & 50 \\
\hline & Head and neck & Q75H, T80I, D29G & 49 \\
\hline & LCNEC & W24C & 49 \\
\hline & Larynx, SQ & D77N, E79G, D29H & 50 \\
\hline & Skin, SQ & G3IA & 50 \\
\hline & Esophagus, SQ & T80K, G8IV, E82L, D27Y & 50 \\
\hline & & D77V or G, E78K, E79K, T80K, G8ID & 51 \\
\hline & Cervical, SQ & E79Q & 51 \\
\hline & Malignant melanoma & L30F & 51 \\
\hline \multirow[t]{4}{*}{ Epigenetic silencing of Keap/ gene } & Lung & Hypermethylation of the Keap / gene & 52 \\
\hline & Colorectal & Hypermethylation of the Keap / promoter & 53 \\
\hline & & region ( $C_{P G}$ island hypermethylation) & \\
\hline & Prostate & $\mathrm{CPG}_{\mathrm{p}}$ island hypermethylation & 46 \\
\hline \multirow[t]{2}{*}{$\begin{array}{l}\text { Accumulation of Keapl-interacting } \\
\text { proteins }\end{array}$} & $\mathrm{HCC}$ & $\begin{array}{l}\text { Phosphorylation of the autophagy-adaptor } \\
\text { protein p62 }\end{array}$ & 54 \\
\hline & & p62 accumulation & 55 \\
\hline Cysteine modification of Keap I & $\begin{array}{l}\text { Type } 2 \text { papillary renal cell } \\
\text { carcinoma }\end{array}$ & $\begin{array}{l}\text { Fumarate accumulation due to mutation in } \\
\text { fumarate hydratase }\end{array}$ & 56 \\
\hline
\end{tabular}

Abbreviations: AD, adenocarcinoma; CC, clear cell carcinoma; CCC, cholangiocellular carcinoma; HCC, hepatocellular carcinoma; LCNEC, large-cell neuroendocrine carcinoma; NSCC, non-small-cell carcinoma; SQ, squamous carcinoma.

\section{Design of Nrf2 modulators Electrophilic modifiers}

Different strategies have been described for the design of Nrf2/Keap1 signaling pathway modulators. Since the Nrf2/ Keap1/ARE pathway is activated in the presence of xenobiotics, especially different reactive species (ROS, RNS, and different electrophiles), the first logical approach was to design compounds with reactive functional groups, which are usually electrophiles, or that contain groups that can be metabolically transformed to electrophilic species. These so-called electrophilic modifiers activate the Nrf2/Keap1/ARE pathway by covalently binding to cysteine residues of the target Nrf2 or Keap1 protein. Nrf2 contains seven highly conserved cysteine residues which were demonstrated to be critically involved in the regulation of oxidant/electrophile-sensing,
Keap1-dependent ubiquitination-proteasomal degradation and transcription activation. ${ }^{57}$ On the other hand, Keap1 contains about 25 cysteine residues required for either Nrf2 activation (Cys151) or suppression (Cys273 and Cys288). ${ }^{57}$ All these residues could be affected by electrophilic species leading to indirect inhibition of Keap1-Nrf2 interaction.

Many structurally diverse electrophiles have been reported to date and are described in detail by some excellent reviews. ${ }^{2,28,58}$ Magesh et al provided a detailed description (with representative examples) of ten chemically distinct classes of indirect small-molecule Keap1-Nrf2 interaction inhibitors, namely Michael acceptors (caffeic acid phenethyl ester (1) (Figure 3), curcumin (2), chalcones), oxidizable diphenols and quinones (quercetin [4]), 

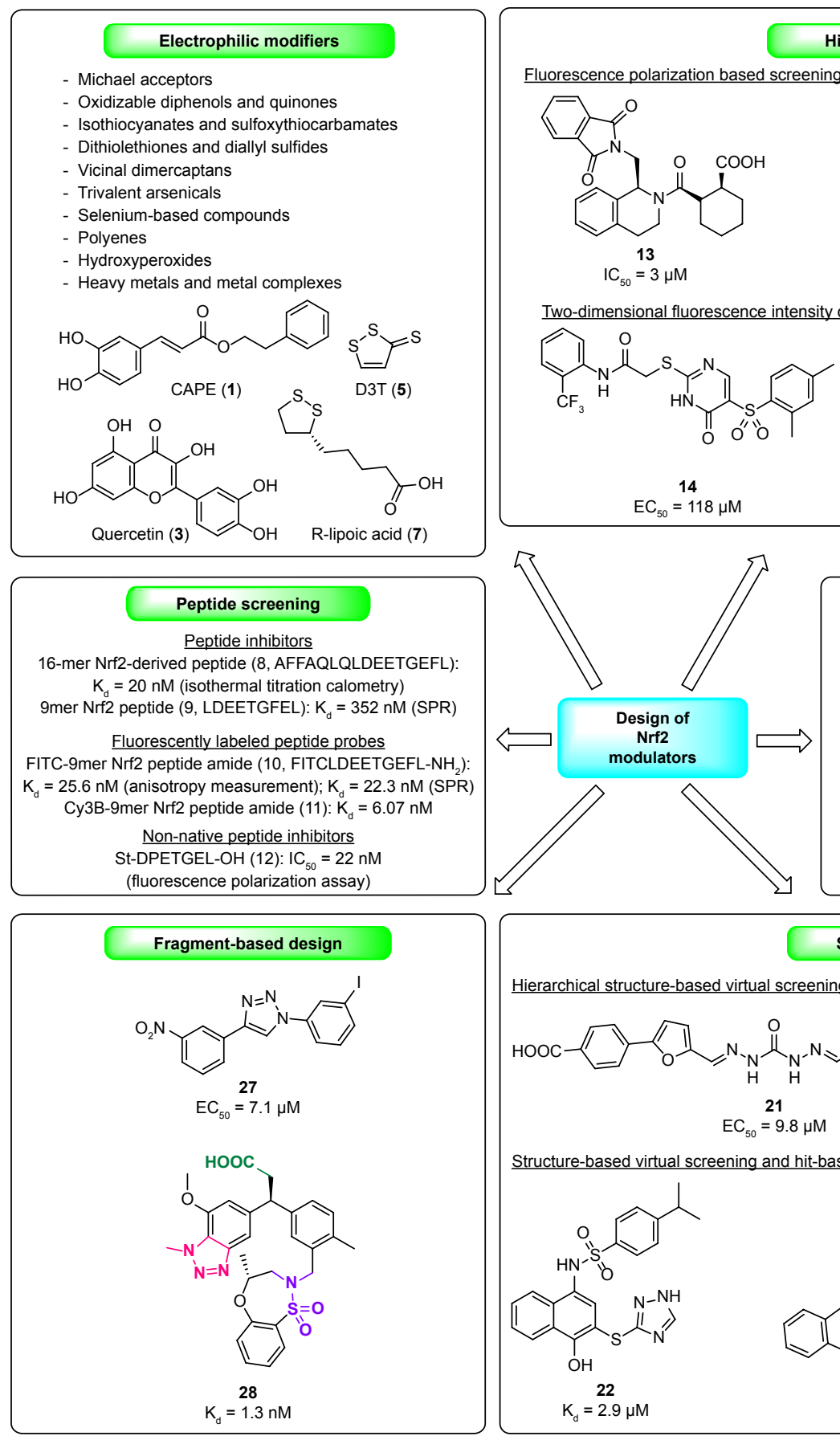

\section{High-throughput screening}

hael acceptors

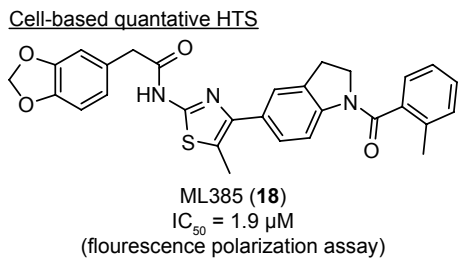

Two-dimensional fluorescence intensity distribution analysis (2D-FIDA)
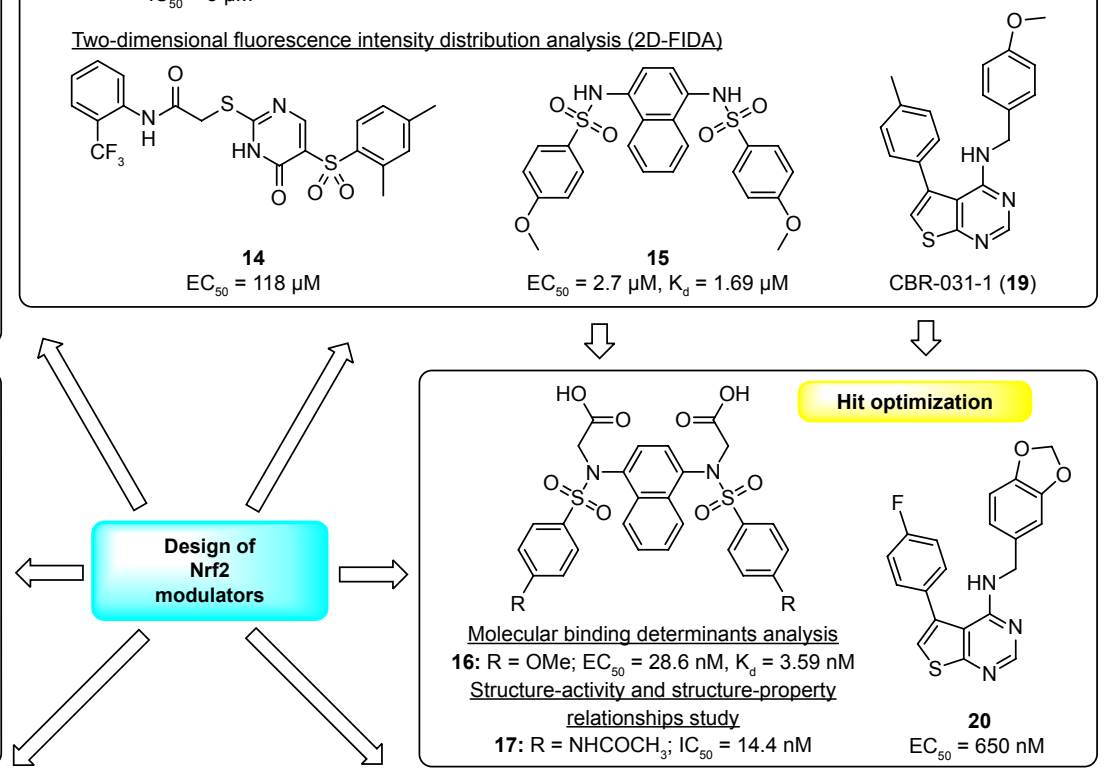

Figure 3 Different strategies used for the design of $\mathrm{Nrf2/KeapI} \mathrm{signaling} \mathrm{pathway} \mathrm{modulators.}$

Abbreviations: CAPE, caffeic acid phenethyl ester; D3T, 3H-I,2-dithiole-3-thione; FIDA, fluorescence intensity distribution analysis; FITC, fluorescein isothiocyanate; HTS, high-throughput screening; SPR, surface plasmon resonance.

isothiocyanates and sulfoxythiocarbamates (sulforaphane [4]), dithiolethiones and diallyl sulfides (3H-1,2-dithiole3-thione (5), diallyl sulfide [6]), vicinal dimercaptans ([R]-lipoic acid [7]), trivalent arsenicals, selenium-based compounds, polyenes, hydroperoxides, and heavy metals and metal complexes. ${ }^{28}$ Although there are large number of "reactive" indirect Nrf2 modulators, their therapeutic potential is low and very limited due to "off-target" side effects caused by the attack on cysteine residues of other important cellular proteins.

Therefore, in the past few years, attention has been paid to develop direct Nrf2 modulators targeting Keap1-Nrf2 PPI. ${ }^{59}$ Different design strategies and techniques (Figure 3) have been used so far to identify the agents that can disrupt Keap1-Nrf2 PPI, such as peptide screening, ${ }^{18,60-65}$ HTS, ${ }^{66-69}$ structure-based design, ${ }^{70-72}$ and fragment-based 
approach (in silico ${ }^{73}$ or experiment-based ${ }^{74,75}$ fragment screening).

\section{Peptide screening}

Initially, the design of Nrf2 modulators started with the synthesis and screening of different peptides. In 2006, the crystal structure of the human Kelch domain bound to a 16 mer peptide (8) derived from its substrate Nrf2 was determined by X-ray crystallography. ${ }^{18}$ The application of ITC enabled the determination of a $\mathrm{K}_{\mathrm{d}}$ value of $20 \mathrm{nM}$ for 8 bound to the Kelch domain of Keap1. According to structural and functional studies, the DxETGE motif was suggested as the principal Keap1-binding site in Nrf2. Later, a series of Nrf2 peptides with the ETGE motif were synthesized to determine the minimal Nrf2 sequence that is required for binding to Keap1 protein. According to binding affinities obtained by SPR-based competition assay, the minimal Nrf2 peptide sequence required for Keap 1 binding is the 9 mer sequence of LDEETGEFL (9) with a $\mathrm{K}_{\mathrm{d}}^{\text {solution }}$ of $352 \mathrm{nM}^{60}$ A year later, a fluorescent probe based on the DxETGE motif was developed (FITC-9mer Nrf2 peptide amide [10]) and optimized to cyanine-labeled 9mer Nrf2 peptide amide (11) and found to be useful as a probe in a HTS assay for the discovery of novel small-molecule inhibitors of Keap1-Nrf2 interactions. ${ }^{61}$ Many other probes and peptide inhibitors have been developed and are summarized in a review by Zhuang et al. ${ }^{62}$ A phage display library approach was also used for the identification of putative peptide ligands with a nonnative sequence motif. ${ }^{63}$ The same group used the standard solid-phase synthesis for the preparation of peptides with modified C- and N-termini and reduced overall charge. ${ }^{64}$ The most potent peptide containing the $\mathrm{C} 18$ fatty acid stearic acid (St-DPETGEL-OH [12]), with an $\mathrm{IC}_{50}$ of $22 \mathrm{nM}$ as determined in a cell-free fluorescence polarization assay, induced the expression of Nrf2-dependent gene products in cells and thus might be used as a starting molecule for the development of peptidomimetic inhibitors. ${ }^{64}$

\section{High-throughput screening}

Due to pharmacological weaknesses of peptides such as limited stability and poor oral bioavailability, ${ }^{76}$ small-molecule inhibitors of Keap1-Nrf2 interaction are more promising for drug development. The small-molecule first-in-class direct inhibitor of Keap1-Nrf2 PPI (13) with an $\mathrm{IC}_{50}$ value of 3 $\mu \mathrm{M}$ was discovered in 2013 by HTS of the NIH Molecular Libraries Probe Production Centers Network library in a homogenous fluorescence polarization assay ${ }^{66} \mathrm{~A}$ year later, an X-ray crystal structure of Keap1 was co-crystallized with the pure stereoisomer $(\mathrm{S}, \mathrm{R}, \mathrm{S})$ of hit compound $13^{77}$ and the binding pose was identified which has paved the way for more efficient development of novel small-molecule Nrf2 modulators. Another HTS approach using a confocal twodimensional fluorescence intensity distribution analysis (2D-FIDA) Nrf2-Keap1 competition assay, led to the discovery of compound $14\left(\mathrm{EC}_{50}\right.$ of $\left.118 \mu \mathrm{M}\right)$ and sulfonamide $15\left(\mathrm{EC}_{50}\right.$ of $\left.2.7 \mu \mathrm{M}\right),{ }^{67}$ which was further optimized on the basis of molecular binding determinants analysis of Keap1 and by using structure-based design to compound 16 with improved ligand affinity $\left(\mathrm{K}_{\mathrm{d}}\right.$ value of $\left.3.59 \mathrm{nM}\right) .{ }^{78}$ Moreover, the effective inhibition of Nrf2-Keap1 interaction $\left(\mathrm{EC}_{50}\right.$ of $28.6 \mathrm{nM}$ ) and activation of the Nrf2 transcription in a dosedependent manner were also confirmed for compound 16 by using a cell-based ARE-luciferase reporter assay and a quantitative reverse transcription PCR. This research clearly demonstrated that small molecules could achieve direct and highly efficient interruption of the Keap1-Nrf2 PPI and that this strategy could be successful for the prevention of cancer and other chronic diseases in the future. Further chemical optimization of compound 16 to 17 , with para-acetamido substituents on the side chain of phenyl rings, provided the optimal balance between inhibition of Nrf2-Keap1 PPI, physicochemical properties, and cellular Nrf2 activity. In addition, in vivo experiments performed in a lipopolysaccharide-challenged mice model also indicated the anti-inflammatory effects of compound $17 .{ }^{79}$

Two other HTS approaches rendered small-molecule inhibitors of Nrf2. A cell-based quantitative HTS of smallmolecule library of approximately 400,000 compounds using a novel $\mathrm{Nrf} 2$ reporter gene assay multiplexed with a cytotoxicity readout was used to identify ML385 (18) as a specific small-molecule inhibitor of Nrf2. ${ }^{68}$ Compound 18 was obtained after basic SAR studies which revealed the importance of an ortho-substituent on the benzoyl group. To evaluate the interaction of 18 with Nrf2 and its influence on DNA-binding activity of the Nrf2-MAFG protein complex, a fluorescence polarization assay using fluorescein-labeled ARE-DNA duplex was developed. In the presence of ML385, anisotropy was decreased in a dose-dependent manner $\left(\mathrm{IC}_{50}\right.$ of $1.9 \mu \mathrm{M}$ ), indicating the dissociation of the Nrf2-MAFG protein complex from fluorescein-labeled ARE-DNA. ${ }^{68}$ Another HTS was conducted to identify small molecules inhibiting deregulated Nrf2 transcriptional activity. ${ }^{69}$ Thienopyrimidine-containing compound CBR-031-1 (19) was selected as a promising hit due to chemical tractability and reproducible broad inhibition of Nrf2-controlled gene expression. An additional SAR study around the 
thienopyrimidine scaffold with approximately $100 \mathrm{com}$ mercially available structural analogs furnished AEM1 (20) with improved potency and metabolic stability. Compound 20 significantly decreased the ARE-luciferase signal and inhibited HO-1 suppression at both transcript and protein levels with an $\mathrm{EC}_{50}$ of approximately $650 \mathrm{nM}^{69}$

\section{Structure-based design}

A successful application of structure-based design was also reported for the discovery of small-molecule Nrf2 modulators. Based on the receptor-ligand binding model of Keap1-Nrf2, hierarchical structure-based virtual screening was performed by Sun et al. ${ }^{70}$ Compound 21 was discovered as a potent Nrf2-Keap1 PPI $\left(\mathrm{EC}_{50}\right.$ of $\left.9.80 \mu \mathrm{M}\right)$ at both target-based and cell-based level. In this study, it was also demonstrated that long-acting and less toxic effect could be achieved by Nrf2 activation via direct inhibitors of Keap1-Nrf2 PPI in comparison to the covalent binding-based Nrf2 activators. Three classes of novel inhibitors (the most potent representative examples are 22-24) disrupting Keap1-Nrf2 PPI were successfully identified by rapid structure-based virtual screening and hit-based substructure search. ${ }^{71}$ The obtained $\mathrm{K}_{\mathrm{d}}$ values were in the low micromolar range from 2.9 (compound 22) to $77.8 \mu \mathrm{M}$, and furthermore, additional cell-based mechanism studies supported the disruption of Keap1-Nrf2 PPI. Another in silico screening of in-house and commercially available compounds performed on the crystal structure of the Kelch domain of human Keap1 in complex with the ETGE peptide of Nrf2 yielded 65 compounds. ${ }^{72}$ After binding ability evaluation by SPR, 27 compounds were active and the most promising one was ligand X (25). After further structural improvement, where the phenol moiety of 25 was replaced by the oxyacetic to mimic the side chain of the glutamic acid residue in the ETGE peptide, ligand 1 (26) was synthesized and later crystallized in two crystal structures at $2.1 \AA$ resolution. ${ }^{72}$

\section{Fragment-based design}

The available crystal structures ${ }^{18,80}$ of the human Keap1 Kelch domain were also used for an in silico fragment-based approach to discover 1,4-diaryl-1,2,3-triazole inhibitors of the Keap1-Nrf2 PPI. ${ }^{73}$ The most active compound 27 showed reversible binding to Keap1, similar cell-based activity to indirect Keap1-Nrf2 inhibitor sulforaphane (4) but without any cytotoxic activity over a wide concentration range. Another use of a fragment-based approach to directly target the Keap1 Kelch-Nrf2 interaction was reported by Davies et al. ${ }^{74}$ Three distinct "hot-spots" were identified within the Nrf2-binding pocket of Keap1 by X-ray crystallographic screen of approximately 330 fragments. Further optimization of weak fragment hits led to a promising lead compound 28 that implemented the three-point pharmacophore (acid, aromatic acceptor, and sulfonamide) from fragment screening and exhibited very high affinity for the Keap1 Kelch domain $\left(\right.$ ITC $\left.\mathrm{K}_{d}=1.3 \mathrm{nM}\right) .{ }^{74}$ Furthermore, the activation of the Nrf2 antioxidant response in cellular and in vivo models was also observed.

\section{Inhibitors of the Keap I-Nrf2 interactions}

Most of the Nrf2 modulators are the inhibitors of the Keap1Nrf2 interactions, and some of them have been already crystallized in a complex with Keap $1 .^{67,74,77,81-83}$ The majority of PPI inhibitors share similar interface, which could be seen in Figure 4. Some mimic the $\beta$-turn of Nrf2-derived peptide (ETGE motif) interacting with some of the previously mentioned Keap1 residues Ser363, Arg380, Asn382, Arg415, Arg483, Ser508, Gln530, and Ser602 (Figure 2), whereas the others bind deeper within the pocket defined by residues Ala556, Gly603, Gly364, Gly462, and Gly509. According to available crystal structures, there is still some space left for further optimization, perhaps with the introduction of fragments that interact with additional residues in the extension of the pocket, screening of other turn mimetics, or maybe even the introduction of reactive functional groups to design covalent inhibitors.

\section{Nrf2 modulators for cancer prevention and therapy}

Cancer chemoprevention is associated with the application of natural or synthetic chemical agents to minimize the risk of cancer development. ${ }^{29,30}$ One of the possible and the most commonly described approaches to achieve effective cancer chemoprevention involves the induction of cytoprotective and detoxifying enzymes. The expression of these inducible genes is regulated by the Nrf2/Keap1 signaling pathway. Nrf2 is substantially involved in the upregulation of these genes in response to oxidative stress and the application of natural or synthetic compounds. There have been a few recent reviews about natural compounds which have the ability to induce genes involved in antioxidant defense through activating the Nrf2/Keap1 signaling pathway. ${ }^{31}$

\section{Natural Nrf2 activators}

Two major classes of natural compounds acting as promising chemopreventive agents are phenolic and sulfur-containing compounds. ${ }^{29}$ Phenolic compounds are well known for multiple biological activities including anticarcinogenic 


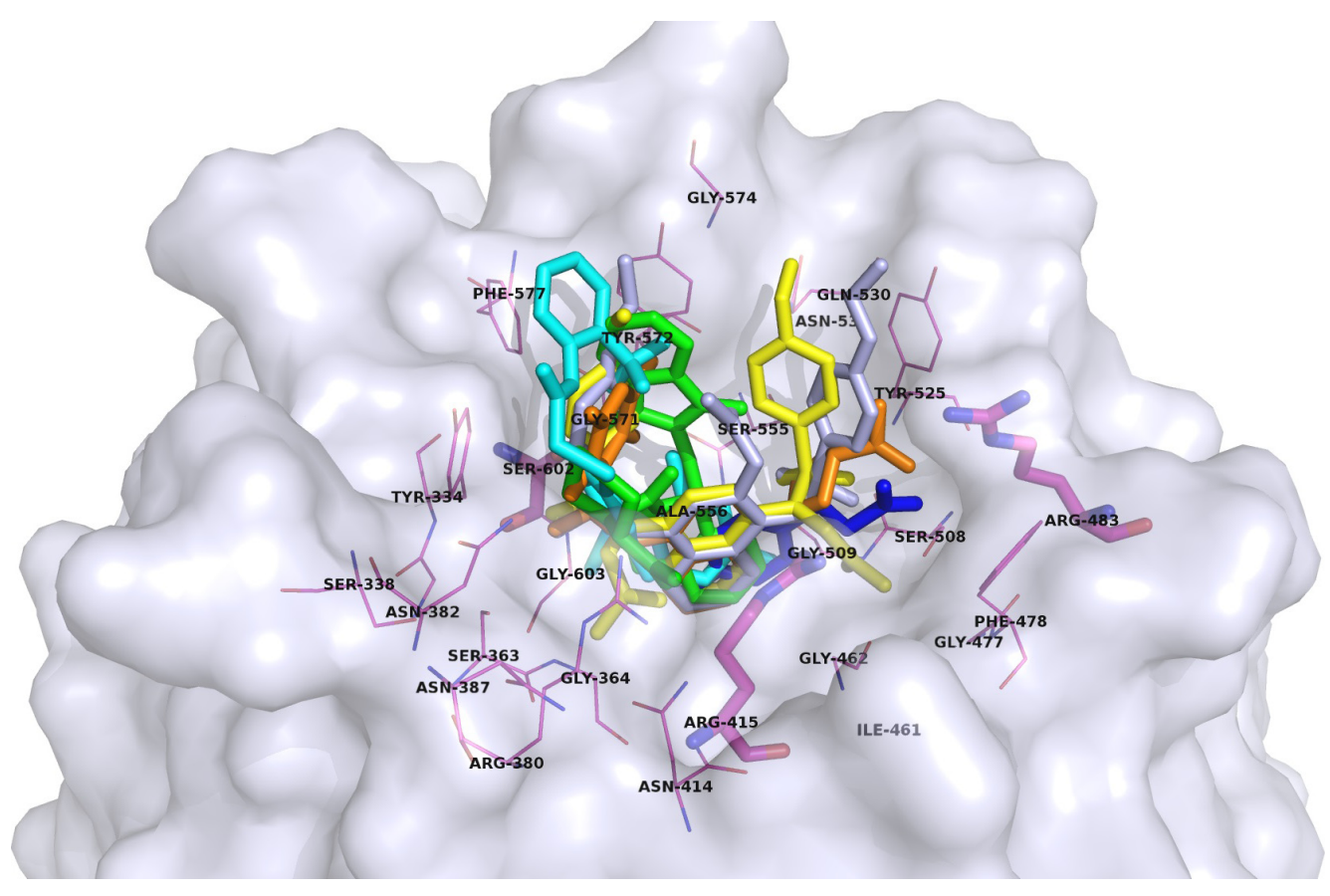

Figure $4 \mathrm{~A}$ surface presentation of the Kelch domain (gray) in complex with inhibitors of the Keapl-Nrf2 interactions from crystal structures: (IS,2R)-2-\{[(IS)-I-[(I,3dioxo-I,3-dihydro-2H-isoindol-2-yl)methyl]-3,4-dihydroisoquinolin-2(IH)-yl]carbonyl\}cyclohexanecarboxylic acid (I3) 77 (green, PDB ID: 4L7B), 2-(\{5-[(2,4-dimethylphenyl) sulfonyl]-6-oxo-I,6-dihydropyrimidin-2-yl\}sulfanyl)- $N$-[2-(trifluoromethyl)phenyl]acetamide (I4) ${ }^{67}$ (cyan, PDB ID: 4IN4), 2,2'-(naphthalene-I,4-diylbis(((4-methoxyphenyl) sulfonyl)azanediyl)) diacetamide ${ }^{81}$ (yellow, PDB ID: 4XMB), N, $N^{\prime}$-[2-(2-oxopropyl)naphthalene-I,4-diyl]bis(4-ethoxybenzenesulfonamide) (5I) ${ }^{82}$ (light blue, PDB ID: 4ZY3), (3S)-I-(4-\{[(2,3,5,6-tetramethylphenyl)sulfonyl]amino\}naphthalen-I-yl)pyrrolidine-3-carboxylic acid ${ }^{83}$ (orange, PDB ID: 5CG]), and 3-(4-chlorophenyl)propanoic acid ${ }^{74}$ (blue, PDB ID: 5FNQ).

Abbreviation: PBD, Protein Data Bank.

activity. ${ }^{84,85}$ Induction of phase II detoxifying and antioxidant defense enzymes via Nrf2/Keap1 signaling pathway has been recognized as one of the most important molecular mechanisms for cancer chemopreventive effects of polyphenols. ${ }^{85}$ Curcumin (2) $)^{86}$ and resveratrol (29) 87,88 (Figure 5) have been extensively studied as natural compounds with chemopreventive properties in several types of cancer. The inhibition of proliferation, invasion, angiogenesis, and metastasis of different cancers through interaction with multiple cell signaling proteins is discussed in a review by Kunnumakkara et al. ${ }^{89}$ In a recent study, it was suggested that curcumin's inhibition of the proliferation of breast cancer cells is achieved via Nrf2-mediated downregulation of Fen1 expression. ${ }^{90}$ However, safety (especially long-term toxicity) and poor pharmacokinetic properties (in particular, low systemic bioavailability) have to be considered for 2 to be used as a dietary supplement. ${ }^{91,92}$ Even though no major toxicity has been found in short-term studies in humans, a long-term toxicity study conducted in rats and mice does raise some concern about safety of $2 .{ }^{93}$ Despite the high oral doses of 2 , the plasma concentrations still remained very low, typically in the nanomolar range, ${ }^{91}$ which limits the therapeutic potential of orally administered 2 . On the other hand, resveratrol (29) was able to inhibit estrogen-induced breast carcinogenesis via induction of the Nrf2-mediated protective pathway. ${ }^{94}$ Induction of Nrf2 signaling by 29 leads to transactivation of antioxidant and phase II detoxifying enzymes, and enables protection against phase I enzyme-activated carcinogens and associated carcinogenicity. ${ }^{95}$ However, due to low bioavailability and rapid clearance of 29 , to be used therapeutically as a chemopreventive agent, it is necessary to develop analogs with improved bioavailability and more potent Nrf2 activation.

The suppression of tumorigenesis in several chemicalinduced animal carcinogenesis models was also demonstrated for green tea polyphenols. Epigallocatechin-3-gallate (30) and epicatechin-3-gallate (31) are known Nrf2 activators which showed potent induction of ARE-mediated luciferase activity. It was suggested that the induction of the ARE reporter gene is structurally related to the 3 -gallate group. ${ }^{96}$ Isothiocyanates (such as sulforaphane [4]), which are present in cruciferous vegetables, and diallyl sulfide (6), a flavor compound derived from garlic, are sulfur-containing compounds with chemopreventive properties mediated by the Nrf2/ARE pathway. ${ }^{30}$ Sulforaphane (4) has been recognized as a chemopreventive agent due to its ability to induce phase II detoxifying enzymes and to inhibit phase I enzymes involved in the activation of carcinogens. ${ }^{30}$ In comparison with curcumin (2) 


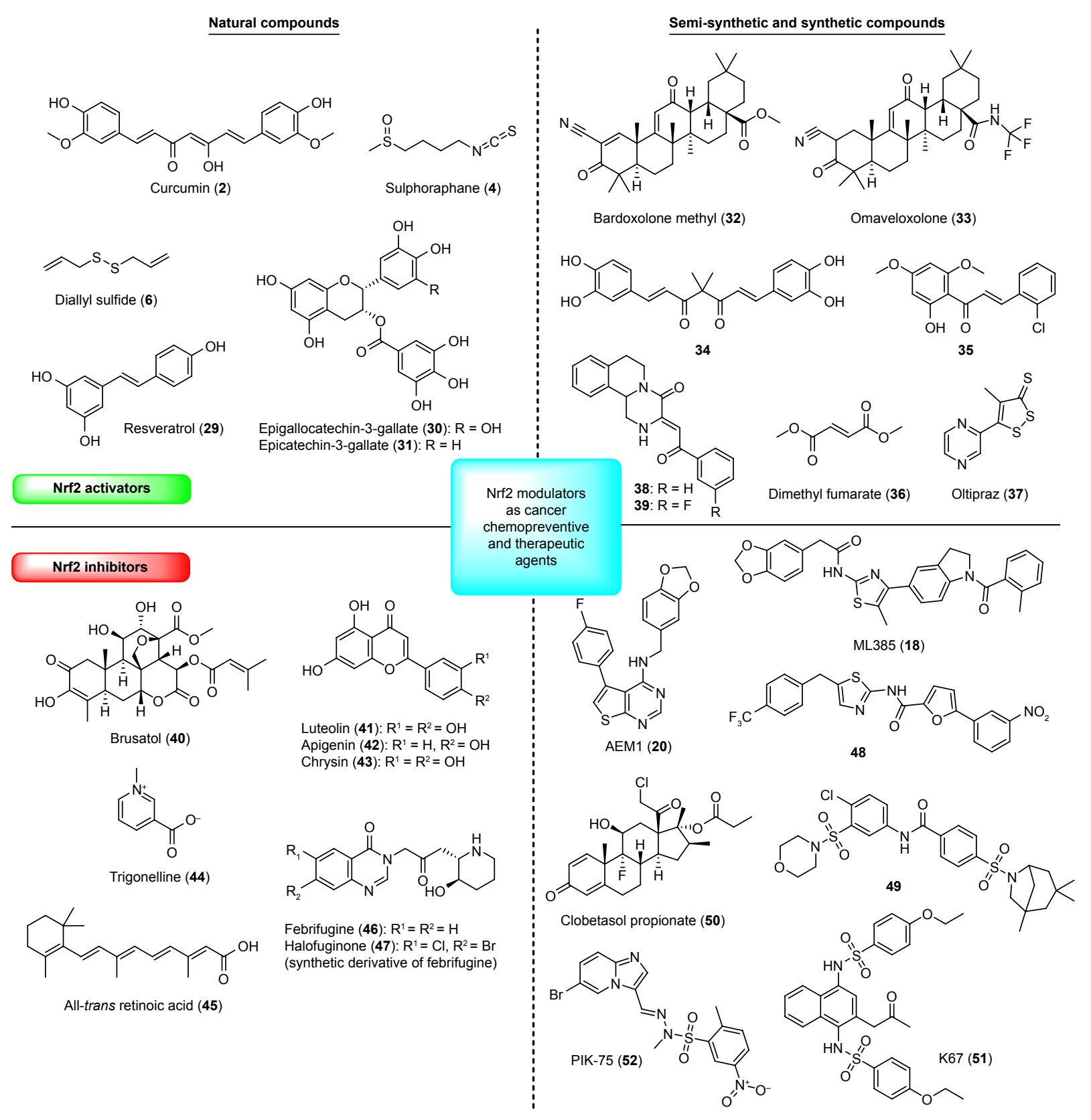

Figure $5 \mathrm{Natural}$ and synthetic Nrf2 modulators as potential cancer chemopreventive and therapeutic agents.

and resveratrol (29), 4 exhibited more potent activation of Nrf2 to induce the expression of a battery of cytoprotective genes. Furthermore, the lipophilic nature and low molecular weight of 4 offer significantly better bioavailability than the polyphenol-based Nrf2 activators. ${ }^{97}$ The absolute bioavailability of dietary doses of 4 following oral and intravenous administration was determined in rats. After oral administration, 4 was rapidly absorbed and achieved high absolute bioavailability at low dietary doses; however, dose-dependent pharmacokinetics was observed with bioavailability decreasing with increasing dose. ${ }^{98}$ In another study with 65 human volunteers, orally administrated 4 effectively induced mucosal phase II enzyme expression in the upper airway without significant adverse events. ${ }^{99}$ Two different studies with single dose of a broccoli sprout preparation containing about 200 $\mu \mathrm{mol}$ of 4 were conducted in human volunteers. ${ }^{100,101}$ Rapid absorption of isothiocyanates with peak concentrations from 0.943 to $2.27 \mu \mathrm{mol} / \mathrm{L}$ in plasma, serum, and erythrocytes was observed after 1 hour, and declined following first-order kinetics with a half-life of 1.77 hours. ${ }^{100}$ When 4 was given to eight healthy women undergoing reduction mammoplasty, dithiocarbamate metabolites were readily measurable in 
breast tissue at concentrations of 1.45-2.00 pmol/mg tissue. ${ }^{101}$ In addition, NQO1 and HO-1 transcripts, as well as NQO1 enzymatic activity, were measured in human breast tissue. All clinical studies with broccoli preparation are extensively summarized in a review by Dinkova-Kostova et al. ${ }^{102}$ Efficacy, safety, and distribution in selected tissues suggest 4 has a great potential for the chemoprevention of different types of cancer. Sulforaphane (4) as a pleiotropic natural compound acts on several targets and pathways directly or indirectly connected to cancer (summarized in a recent review by Russo et al), ${ }^{103}$ and this multi-target activity is definitely an advantage in case of a complex disease, such as cancer. However, due to recent findings about the oncogenic role of Nrf 2 in cancer cells, the therapeutic or other use of 4 should be considered with caution due to its ability of potent activation of Nrf2. More in vivo studies are still needed to confirm the beneficial and safe use of 4 as a chemopreventive agent or adjuvant without the risk of developing serious side effects.

Numerous other natural compounds that are able to induce detoxifying enzymes through Nrf2-signaling pathway have been reported as potential cancer chemopreventive agents. ${ }^{31,32}$ The list of the so-called natural inducers has been increasing each day; however, more studies, including the elucidation of the detailed molecular mechanisms, are needed for their possible application in cancer chemoprevention.

\section{Semisynthetic and synthetic Nrf2 activators}

Semisynthetic and synthetic analogs are more likely to be used in clinical practice. Some have been already investigated in clinical trials. ${ }^{22,104}$ For example, bardoxolone methyl (CDDO-Me, 32), a semisynthetic triterpenoid originated from the natural product oleanolic acid, potently induces Nrf2 and has been investigated in different types of cancer (including leukemia and solid tumors). ${ }^{22,105,106}$ In a Phase I first-in-human trial of 32 in patients with lymphomas and advanced solid tumors, objective tumor responses and pharmacodynamic effects were observed. However, the Phase III trial of 32 was discontinued in 2012 due to severe cardiovascular side effects. Nevertheless, synthetic triterpenoids offer great potential for further development as anticancer agents. Many patents involving 32 analogs have been filed in the recent years. ${ }^{104}$ Omaveloxolone (33) was reported as one of the most potent synthetic triterpenoid analogs inducing ARE activity over 16-fold at $62.5 \mathrm{nM}$ in an Nrf2-GSTARE luciferase reporter assay. Early clinical trials for the oral treatment of melanoma and non-small-cell lung cancer have been in progress. Recently, the first-in-human Phase
I clinical trial of patients with advanced solid tumors was conducted and showed favorable tolerability at biologically active doses. ${ }^{107}$ No dose-limiting toxicities were detected for 33 at four dose levels up to $15 \mathrm{mg}$ given orally once daily. Furthermore, rapid absorption and proportional increases in exposure across dose levels were observed for 33. General tendency toward time- and dose-dependent activation of $\mathrm{Nrf} 2$ antioxidant genes was observed in this study. Further investigations of 33 in cancer are supported and will determine its efficacy and potential therapeutic use for the treatment of cancer. Recently, a Phase Ib/II study of omaveloxolone in combination with checkpoint inhibitors in patients with unresectable or metastatic melanoma was conducted. ${ }^{108}$ No dose-limiting toxicities were observed for 33, and it was well tolerated at doses up to $150 \mathrm{mg}$. Initial efficacy data showed that checkpoint inhibitors resistance may be overcome in the presence of 33. According to current clinical data, 33 definitely shows a high potential and further clinical studies will hopefully confirm its beneficial effects, not only for the treatment of cancer but also for the treatment of other pathologies, such as neurological disorders. ${ }^{109}$

In another study, natural curcumin-directed Nrf2 activators were synthesized and evaluated for their cytoprotective effects. ${ }^{110}$ The catechol-type curcumin analog (compound 34) was selected as one of the most promising compounds due to high stability and cytoprotective activity against the tert-butyl hydroperoxide-induced death of HepG2 cells. According to mechanistic studies, this activity is mediated by the activation of the Nrf2 signaling pathway in the Michael acceptor- and catechol-dependent manners. ${ }^{75}$ Many other synthetic curcumin analogs ${ }^{111}$ have been prepared up to date; however, their chemical and metabolic instability, poor membrane permeability, and extremely low oral bioavailability are just some of the issues that have to be considered in the development of synthetic curcumin analogs as preventive and therapeutic agents. A synthetic chalcone, 2-chloro-4', 6'-dimethoxy-2'-hydroxychalcone (35), was also found to be a potent activator of Nrf2 transcriptional activity with the ability to modulate intracellular levels of GSH. ${ }^{112}$ The study was carried out in a human breast cancer cell line expressing a luciferase reporter gene driven by ARE. Furthermore, it was also observed that chalcones posttranslationally enhance formation of glutamate cysteine ligase holoenzyme. ${ }^{12}$

Among other synthetic Nrf2 activators, much attention has been focused on DMF (36) and oltipraz (37). DMF (Tecfidera ${ }^{\circledR}$; Biogen Inc., Cambridge, MA, USA) is a well-known Nrf2 activator, which has been used in clinics 
for the treatment of multiple sclerosis. ${ }^{113,114}$ Recently, 36 was also identified as a promising Nrf2-DJ-1 axis inhibitor in cancer cells. ${ }^{115}$ At concentrations lower than $25 \mu \mathrm{mol} / \mathrm{L}$, a cytoprotective role due to activation of the Nrf2 antioxidant pathway was observed, whereas at higher concentrations 36 decreased the expression of the Nrf2 protein stabilizer DJ-1 and caused cytotoxicity in several cancer cell lines due to oxidative stress. ${ }^{115}$ Recently, the same research group also discovered that 36 is highly and selectively cytotoxic against patient-derived cancer cell lines harboring a G12V KRAS mutation. ${ }^{116}$ It has been known for a decade that 36 has antiproliferative and proapoptotic properties and can reduce melanoma growth and metastasis in animal models. ${ }^{117}$ Moreover, in two mice models of colon cancer, an antitumoral effect of 36 (administered daily, $20 \mathrm{mg} / \mathrm{kg}$ ) was also observed. ${ }^{115}$ All of these results indicate that 36 has the potential for therapeutic intervention in cancer; however, additional in vivo studies are needed. Another well-studied synthetic Nrf2 activator, which has also entered clinical trials, is 4-methyl-5-[2-pyrazinyl]-1,2-dithiole-3-thione (oltipraz, 37). ${ }^{27}$ Compound 37 is best known for its activity against aflatoxin-induced liver cancer; ${ }^{33}$ however, for potential therapeutic application, further clinical trials are needed to clearly demonstrate the effectiveness of 37 for the prevention of human hepatocarcinomas.

Screening of an in-house database using the luciferase reporter assay led to the discovery of compound 38 , which was determined to be a potent activator of the Nrf2/ARE signaling pathway in a human cancer cell-based and azoxymethane/dextran sodium sulfate mouse model. ${ }^{118}$ Moreover, 38 also significantly inhibited the development of inflammation-associated colorectal adenomas. In addition, structural modifications suggested from the SAR study led to compound 39 with a higher potency to enhance ARE levels. However, further optimization and studies are still needed to develop suitable compounds for therapeutic use. Lastly, in recent years, two interesting patents were published describing the functionalized heteroaryl enones ${ }^{119}$ and pyridopyrazine compounds ${ }^{120}$ as Nrf2 activators and their potential use in the treatment of cancer. ${ }^{104}$

\section{Natural Nrf2 inhibitors}

It has also been shown that prolonged expression of Nrf2 offers protection to cancer cells which can be achieved by inducing the metabolism and efflux of chemotherapeutics. Consequently, both intrinsic and acquired chemoresistance to cancer drugs occur. ${ }^{121}$ Therefore, inhibition of the Nrf2 signaling pathway has also gained more attention in the past few years. ${ }^{122}$ There have been several reports about smallmolecule inhibitors of Nrf2 that display in vivo antitumor activity. ${ }^{104}$ Among natural products, several studies have been performed on brusatol (40), a quassinoid from Brucea javanica. ${ }^{123,124}$ Compound 40 was identified as one of the most potent inhibitors of the Nrf2 signaling pathway which decreases the protein level of Nrf2. The reduction in Nrf2 was observed in many cancer cell lines regardless of the status of Keap1 or Nrf2 being wild type or mutated. ${ }^{123}$ Accordingly, 40 could enhance the cytotoxic effect of chemotherapeutic agents. The recently reported brusatol's mode of action is via inhibition of cap-dependent and cap-independent protein translation having an impact on a great number of other proteins, especially those with a short half-life. Therefore, 40 is not specific to Nrf2 and is more of a global protein synthesis inhibitor. ${ }^{125,126}$ Hall et al ${ }^{127}$ also reported that 40 significantly inhibited DNA, RNA, and protein synthesis in p-388 lymphocytic leukemia cells; however, micromolar concentrations of 40 were used in this study. The nonspecificity of 40 seems to be related to its concentration, which was later showed in the study by Ren et al, ${ }^{128}$ where $20-80 \mathrm{nM}$ of 40 specifically inhibited the protein level of Nrf2 in a dose-dependent manner. Nevertheless, most of the results were obtained only in cancer cell lines and selected animal models. The lack of results (especially in humans), pleiotropic effects, and potential toxicity of 40 limits its possible use. A series of brusatol analogs, which were up to 100 -fold and more less toxic than 40 , have been already synthesized recently. ${ }^{129}$ The development of more specific Nrf2 inhibitors with limited toxicity and off-target effects seems to be the best strategy for the future.

Several other natural small-molecule Nrf2 inhibitors have also been reported, such as the flavonoids luteolin (41), ${ }^{130}$ apigenin (42), ${ }^{131}$ and chrysin (43), ${ }^{132}$ the coffeederived alkaloid trigonelline (44), ${ }^{133}$ and ATRA (45). ${ }^{28}$ In the presence of ATRA, Nrf2 forms a complex with the alpha retinoic acid receptor, which can no longer bind to ARE sequences, thereby blocking the activation of the signaling pathway. ${ }^{27,28}$ In fact, the Nrf2 inhibitory activity of 45 was observed in human breast cancer (MCF-7) cells transfected with an ARE-luciferase reporter construct. ${ }^{134}$ Lastly, inhibition of the Nrf2 transcription factor was also observed by the alkaloid trigonelline (44) which has the potential to be used in combination therapy of highly resistant tumors such as pancreatic cancer. Compound 44 is capable of changing pancreatic cancer cells such that they become more susceptible to apoptosis through decreased proteasomal gene expression and proteasome activity. ${ }^{135}$ 
Another plant alkaloid febrifugine (46), found in the roots of the blue evergreen hydrange, was observed to inhibit Nrf2 activity, as shown by repressed luciferase activity in A549-ARE-Luc cells. ${ }^{136}$ Further studies focused on the less toxic febrifugine derivative halofuginone (47) which rapidly suppressed the accumulation of Nrf2 protein in Nrf2-addicted cancer cells. Furthermore, 47 repressed protein synthesis via an amino acid starvation response elicited by inhibition of prolyl-tRNA synthetase and possess the ability to enhance the sensitivity of Nrf2-addicted cancer cells to anticancer drugs both in vitro and in vivo. Thus, 47 could be used as a chemosensitizer by inhibiting Nrf2 accumulation in various Nrf2-addicted cancers. ${ }^{136}$ However, it should be noted that 47 is a multifaceted molecule with many biological activities (reviewed by Pines and Spector) ${ }^{137}$ and could act on several different targets and pathways, such as inhibition of Smad3 phosphorylation downstream of the TGF $\beta$ signaling pathway. This promiscuity could be problematic in the further development of 47 for a therapeutic use.

\section{Semisynthetic and synthetic Nrf2 inhibitors}

In addition to several natural Nrf2 inhibitors, a few synthetic small-molecule Nrf2 inhibitors have been described. HTS was used to identify small molecules which decrease Nrf2 transcriptional activity at ARE sites. ${ }^{69}$ An additional SAR study of thienopyrimidine-containing compounds to identify analogs with improved potency and metabolic stability showed AEM1 (20) as the most promising compound. Broad suppression of Nrf2-driven genes was observed for 20 when treating A549 cells, the lung adenocarcinoma cell line with an inactivating mutation in Keap1 (G333C) that leads to constitutive Nrf2. Furthermore, 20 was also able to sensitize A549 cells to various chemotherapeutic agents and oxidative stress and led to inhibition of cell growth in vitro and in vivo. The pharmacokinetic profile of orally administered 20 was also determined in mice at a dose of $20 \mathrm{mg} / \mathrm{kg}\left(\mathrm{t}_{1 / 2} 2\right.$ hours; $\mathrm{C}_{\text {max }} 176 \mathrm{ng} / \mathrm{mL} ; \mathrm{AUC}_{(0-24)}$ 453 hours.ng/mL). Treatment with a twice-daily oral $50 \mathrm{mg} /$ $\mathrm{kg}$ dose of 20 resulted in a modest reduction in A549 tumor volume without affecting body weight over the treatment period. However, the potency and pharmacokinetic properties still need to be improved. Small-molecule Nrf2 inhibitors like 20 represent an important starting point and a great potential for the design of alternative anticancer treatments. ${ }^{69}$

Another specific small-molecule Nrf2 inhibitor ML385 (18), discovered by quantitative HTS, ${ }^{68}$ blocked Nrf2 transcriptional activity and showed significant antitumor activity in combination with carboplatin. The ability of 18 to enhance the efficacy of carboplatin and other chemotherapeutic drugs in lung cancer cells renders 18 a great potential for the treatment of advanced non-small-cell lung cancer. Along with ML385 (18), two other compounds (48 and 49) were also extensively described in a patent. ${ }^{138}$ All three compounds were able to suppress the growth of osteosarcoma cells and two different pancreatic cell lines (Panel one and MiaPaCa) as single agents as well as in combination with chemotherapeutic drugs (doxorubicin, gemcitabine). According to in vivo pharmacokinetic studies, all three compounds have a fairly good retention time in the blood and thus possess very good drug-like properties. The pharmacokinetic plasma profiles of compounds 18 and 48 in CD1 mice indicated that in vivo exposure and pharmacokinetics were appropriate for in vivo use. ${ }^{138}$ In a recent study ${ }^{139}$ investigating the protective effects of isoliquiritigenin on acute pancreatitis, the inhibitory effect of 18 on Nrf2 activation was also examined. The results obtained confirmed that 18 actually inhibited nuclear translocation of Nrf2 in pancreatic tissue. Moreover, 18 also showed protective effects in acute pancreatitis via an unknown mechanism. Very little has been known about other biological activities of 18 , so it might be interesting to evaluate its possible effects on the activity of other transcription factors or signaling pathways.

In order to develop potent NRF2 inhibitors for therapeutic use, Choi et a $\mathrm{l}^{140}$ screened around 4,000 clinical compounds. Clobetasol propionate (50) was identified as the most potent Nrf2 inhibitor. The induction of oxidative stress and potent suppression of the anchorage-independent growth of tumors with Keap1 mutation was observed for 50. Furthermore, potent in vitro and in vivo inhibition of tumor harboring mutations in Keap1 that are frequently observed in a lung cancer was determined for clobetasol propionate alone or in combination with rapamycin. The authors of this study suggested that 50 could be used as a repurposed therapeutic agent for cancers with high Nrf2 activity. ${ }^{140}$

Phosphorylated p62 is able to bind with high affinity to Keap1, thus inhibiting Keap1-driven ubiquitination of Nrf2 which results in stabilization of $\mathrm{Nrf} 2$ and its translocation into nucleus. ${ }^{82}$ It is known that dysregulation of the p62-Keap1Nrf2 axis has been implicated in the development of cancer. Indeed, Nrf2 activation by phosphorylated p62 contributes to tumor growth which was demonstrated by a significant reduction of tumor size in liver-specific autophagy-deficient mice by simultaneous deletion of p62 or Nrf2. Therefore, a specific inhibitor of phosphorylated p62-Keap1 interaction would facilitate the binding of Keap1 and subsequent degradation of $\mathrm{Nrf2}$, and thus could be used as a potential 
anticancer drug. ${ }^{34}$ In a chemical screen, Saito et al ${ }^{82}$ identified $\mathrm{N}$-[2-acetonyl-4-(4-ethoxybenzenesulfonylamino) naphthalene-1-yl]-4-ethoxybenzene-sulfonamide $(\mathrm{K} 67,51)$ as a small-molecule inhibitor of the interaction between phosphorylated p62 and Keap1. Their results clearly indicated that treatment of human hepatocellular carcinoma cells with 51 suppressed proliferation and reduced tolerance to an anticancer drug. Therefore, with some further structural improvement of 51 and due to its lower solubility, this type of inhibitor could be used as drugs against cancer cells resistant to anticancer agents in a manner that depends upon $\mathrm{p} 62$.

Blocking the Nrf2 signaling pathway by small-molecule inhibitors is also a very promising therapeutic approach for the treatment of pancreatic cancers. ${ }^{141}$ In a recent study, AsPC-1 cells were transfected with a luciferase reporter gene construct containing the ARE from NQO1 gene and treated with various kinase inhibitors. PIK-75, which is known as a PI3K/DNA-PK inhibitor (52), was identified as a potent inhibitor of Nrf2 which reduced its protein levels and induced its proteasomemediated degradation in human pancreatic cancer cells. Furthermore, 52 potentiated the antitumor effect of gemcitabine both in vitro and in vivo indicating its potential benefit in treating pancreatic cancer in combination with gemcitabine. ${ }^{141}$

\section{Conclusion and perspectives}

It is now evident that the Nrf2/Keap1 signaling pathway is the key player in regulating oxidative stress which may contribute to tumor formation. Nrf2 induces the expression of a battery of cytoprotective genes, thereby being able to eliminate ROS, carcinogens, and many other DNA-damaging agents. Modulation of the activity of Nrf2 thus represents a novel modern strategy for cancer chemoprevention and therapy. However, many studies showed that Nrf2 plays a dual role in cancer being capable of acting as a tumor suppressor in one way and as a proto-oncogene in another. Many factors including tight control of Nrf2 activity, cell types, and special tumor microenvironment regulate the switch between pro-oncogenic and anticancer role of $\mathrm{Nrf} 2$. It is now evident that activation of the $\mathrm{Nrf}$ /Keap1 signaling pathway in cancer cells can lead to the metabolic inactivation of antitumor agents and a decrease of their intracellular concentration. Thus, the question remains: should we develop Nrf2 activators or inhibitors? All of the important features mentioned above have to be considered when designing novel Nrf2 modulators. However, due to the many recent findings about the oncogenic role of $\mathrm{Nrf} 2$, the design and development of novel selective inhibitors of Nrf2/Keap1 pathway might present a better strategy for cancer prevention and therapy.
Different design strategies for modulating the Nrf2/Keap1 signaling pathway have been used to date, from electrophilic modifiers, peptide and natural products screening, and HTS to structure-based design and in silico fragment-based approach. Targeting Keap1-Nrf2 PPI has become one of the most popular design strategies in the past 10 years. Many Nrf2 modulators have been discovered by starting from natural compounds and continuing to small-molecule semisynthetic and synthetic compounds. Some of them have already been investigated in clinical trials (eg, DMF, omaveloxolone, oltipraz, ML385), and basic in vivo pharmacokinetic studies have been performed. Nevertheless, inevitable "off-target" side effects for electrophilic modifiers, and chemical and/or metabolic instability, poor membrane permeability and low oral bioavailability for most of natural compounds, give the key advantage and higher potential to synthetic compounds. Additional in vitro and in vivo studies to gain insights and to understand the mechanism of Nrf2 modulation are needed to be successful in the development of Nrf2 modulators for cancer chemoprevention and therapy.

\section{Abbreviations}

ARE, antioxidant response element; ATRA, all-trans retinoic acid; BTB, Broadcomplex, Tramtrack, and Bric-a-Brac; DMF, dimethyl fumarate; GSH, glutathione; HTS, high-throughput screening; ITC, isothermal titration calorimetry; Keap1, Kelchlike ECH-associated; protein 1; Nrf2, nuclear factor E2-related factor 2; PPI, protein-protein interaction; RNS, reactive nitrogen species; ROS, reactive oxygen species; SAR, structureactivity relationship; SPR, surface plasmon resonance.

\section{Acknowledgments}

The authors thank Professor Frank M Scalzo for critical reading of the manuscript and Doctor Marko Jukič for preparation of Figures 2 and 4.

\section{Disclosure}

The authors report no conflicts of interest in this work.

\section{References}

1. Siegel RL, Miller KD, Jemal A. Cancer statistics, 2015. CA Cancer J Clin. 2015;65(1):5-29.

2. Ma X, Yu H. Global burden of cancer. Yale J Biol Med. 2006;79(3-4): 5-94.

3. Huang B, Zhao J, Unkeless JC, Feng ZH, Xiong H. TLR signaling by tumor and immune cells: a double-edged sword. Oncogene. 2008;27(2): 218-224.

4. Gorrini C, Harris IS, Mak TW. Modulation of oxidative stress as an anticancer strategy. Nat Rev Drug Discov. 2013;12(12):931-947.

5. Ma Q. Transcriptional responses to oxidative stress: Pathological and toxicological implications. Pharmacol Ther. 2010;125(3):376-393. 
6. Valko M, Rhodes CJ, Moncol J, et al. Free radicals, metals and antioxidants in oxidative stress-induced cancer. Chem Biol Interact. 2006; 160(1): $1-40$.

7. Stępkowski TM, Kruszewski MK. Molecular cross-talk between the NRF2/KEAP1 signaling pathway, autophagy, and apoptosis. Free Radic Biol Med. 2011;50(9):1186-1195.

8. Fuse Y, Kobayashi M. Conservation of the Keap1-Nrf2 System: An evolutionary journey through stressful space and time. Molecules. 2017;22(3):436

9. Moi P, Chan K, Asunis I, Cao A, Kan YW. Isolation of NF-E2related factor 2 (Nrf2), a NF-E2-like basic leucine zipper transcriptional activator that binds to the tandem NF-E2/AP1 repeat of the beta-globin locus control region. Proc Natl Acad Sci U S A. 1994; 91(21):9926-9930.

10. Kansanen E, Kuosmanen SM, Leinonen H, Levonen A-L. The Keap1Nrf2 pathway: Mechanisms of activation and dysregulation in cancer. Redox Biol. 2013;1(1):45-49.

11. Taguchi K, Motohashi H, Yamamoto M. Molecular mechanisms of the Keap1-Nrf2 pathway in stress response and cancer evolution. Genes Cells. 2011;16(2):123-140.

12. Moi P, Chan K, Asunis I, Cao A, Kan YW. Isolation of NF-E2-related factor 2 (Nrf2), a NF-E2-like basic leucine zipper transcriptional activator that binds to the tandem NF-E2/AP1 repeat of the beta-globin locus control region. Proc Natl Acad Sci U S A. 1994;91(21):9926-9930.

13. Itoh K, Wakabayashi N, Katoh Y, et al. Keap1 represses nuclear activation of antioxidant responsive elements by Nrf2 through binding to the amino-terminal Neh2 domain. Genes Dev. 1999;13(1):76-86.

14. Itoh K, Mimura J, Yamamoto M. Discovery of the Negative Regulator of Nrf2, Keap1: A Historical Overview. Antioxid Redox Signal. 2010;13(11): 1665-1678

15. Itoh K, Tong KI, Yamamoto M. Molecular mechanism activating nrf2keap1 pathway in regulation of adaptive response to electrophiles. Free Radic Biol Med. 2004;36(10):1208-1213.

16. Pandey P, Singh AK, Singh M, et al. The see-saw of Keap1-Nrf2 pathway in cancer. Crit Rev Oncol Hematol. 2017;116:89-98.

17. Tong KI, Katoh Y, Kusunoki H, et al. Keap1 recruits Neh2 through binding to ETGE and DLG motifs: Characterization of the two-site molecular recognition model. Mol Cell Biol. 2006;26(8):2887-2900.

18. Lo SC, Li X, Henzl MT, Beamer LJ, Hannink M. Structure of the Keap1:Nrf2 interface provides mechanistic insight into Nrf2 signaling. Embo J. 2006;25(15):3605-3617.

19. Hörer S, Reinert D, Ostmann K, Hoevels Y, Nar H. Crystal-contact engineering to obtain a crystal form of the Kelch domain of human Keap1 suitable for ligand-soaking experiments. Acta Crystallogr Sect F Struct Biol Cryst Commun. 2013;69(6):592-596.

20. Canning P, Sorrell FJ, Bullock AN. Structural basis of Keap1 interactions with Nrf2. Free Radic Biol Med. 2015;88(Pt B):101-107.

21. Gao B, Doan A, Hybertson BM. The clinical potential of influencing Nrf2 signaling in degenerative and immunological disorders. Clin Pharmacol. 2014;6:19-34.

22. Lu MC, Ji JA, Jiang ZY, You QD. The Keap1-Nrf2-ARE pathway as a potential preventive and therapeutic target: An Update. Med Res Rev. 2016;36(5):924-963.

23. Milkovic L, Zarkovic N, Saso L. Controversy about pharmacological modulation of Nrf2 for cancer therapy. Redox Biol. 2017;12:727-732.

24. Krajka-Kuźniak V, Paluszczak J, Baer-Dubowska W. The Nrf2-ARE signaling pathway: An update on its regulation and possible role in cancer prevention and treatment. Pharmacol Rep. 2017;69(3):393-402.

25. Ma Q. Role of Nrf2 in oxidative stress and toxicity. Annu Rev Pharmacol Toxicol. 2013;53(1):401-426.

26. Lau A, Villeneuve N, Sun Z, et al. Dual roles of Nrf2 in cancer. Pharmacol Res. 2008;58(5-6):262-270.

27. Menegon S, Columbano A, Giordano S. The dual roles of NRF2 in cancer. Trends Mol Med. 2016;22(7):578-593.

28. Magesh S, Chen Y, Hu L. Small molecule modulators of Keap1-Nrf2ARE pathway as potential preventive and therapeutic agents. Med Res Rev. 2012;32(4):687-726.
29. Sanders K, Moran Z, Shi Z, et al. Natural products for cancer prevention: Clinical update 2016. Semin Oncol Nurs. 2016;32(3):215-240.

30. Kou X, Kirberger M, Yang Y, Chen N. Natural products for cancer prevention associated with Nrf2-ARE pathway. Food Sci Hum Wellness. 2013;2(1):22-28.

31. Zhao CR, Gao ZH, Qu XJ. Nrf2-ARE signaling pathway and natural products for cancer chemoprevention. Cancer Epidemiol. 2010; 34(5):523-533.

32. Catanzaro E, Calcabrini C, Turrini E, et al. Nrf2: a potential therapeutic target for naturally occurring anticancer drugs? Expert Opin Ther Targets. 2017;21(8):781-793.

33. Zhang Y, Gordon GB. A strategy for cancer prevention: stimulation of the Nrf2-ARE signaling pathway. Mol Cancer Ther. 2004;3(7): 885-893.

34. Taguchi K, Yamamoto M. The KEAP1-NRF2 System in Cancer. Front Oncol. 2017;7:85.

35. Pitot HC, Goldsworthy T, Moran S. The natural history of carcinogenesis: Implications of experimental carcinogenesis in the genesis of human cancer. J Supramol Struct Cell Biochem. 1981;17(2):133-146.

36. Klaunig JE, Kamendulis LM. The role of oxidative stress in carcinogenesis. Annu Rev Pharmacol Toxicol. 2004;44:239-267.

37. Ziech D, Franco R, Pappa A, Panayiotidis MI. Reactive Oxygen Species (ROS) - Induced genetic and epigenetic alterations in human carcinogenesis. Mutat Res Fundam Mol Mech Mutagen. 2011;711(1-2):167-173.

38. Visconti R, Grieco D. New insights on oxidative stress in cancer. Curr Opin Drug Discov Devel. 2009;12(2):240-245.

39. van der Wijst MGP, Brown R, Rots MG. Nrf2, the master redox switch: The Achilles' heel of ovarian cancer? Biochim Biophys Acta. 2014;1846(2):494-509.

40. Nguyen T, Nioi P, Pickett CB. The Nrf2-antioxidant response element signaling pathway and its activation by oxidative stress. J Biol Chem. 2009;284(20):13291-13295.

41. Padmanabhan B, Tong KI, Ohta T, et al. Structural basis for defects of Keap 1 activity provoked by its point mutations in lung cancer. Mol Cell. 2006;21(5):689-700.

42. Ohta T, Iijima K, Miyamoto M, et al. Loss of Keap1 function activates Nrf2 and provides advantages for lung cancer cell growth. Cancer Res. 2008;68(5):1303-1309.

43. Yoo NJ, Kim HR, Kim YR, An CH, Lee SH. Somatic mutations of the KEAP1 gene in common solid cancers. Histopathology. 2012;60(6): 943-952.

44. Singh A, Misra V, Thimmulappa RK, et al. Dysfunctional KEAP1NRF2 interaction in non-small-cell lung cancer. PLoS Med. 2006; 3(10):e420.

45. Nioi P, Nguyen T. A mutation of Keap1 found in breast cancer impairs its ability to repress Nrf2 activity. Biochem Biophys Res Commun. 2007; 362(4):816-821.

46. Zhang P, Singh A, Yegnasubramanian S, et al. Loss of Keap1 function in prostate cancer cells causes chemo- and radio-resistance and promotes tumor growth. Mol Cancer Ther. 2010;9(2):336.

47. Shibata T, Kokubu A, Gotoh M, et al. Genetic alteration of Keap1 confers constitutive Nrf2 activation and resistance to chemotherapy in gallbladder cancer. Gastroenterology. 2008;135(4):1358-1368.

48. Konstantinopoulos PA, Spentzos D, Fountzilas E, et al. Keap1 mutations and Nrf2 pathway activation in epithelial ovarian cancer. Cancer Res. 2011;71(15):5081-5089.

49. Shibata T, Ohta T, Tong KI, et al. Cancer related mutations in NRF2 impair its recognition by Keap1-Cul3 E3 ligase and promote malignancy. Proc Natl Acad Sci US A. 2008;105(36): 13568-13573

50. Kim YR, Oh JE, Kim MS, et al. Oncogenic NRF2 mutations in squamous cell carcinomas of oesophagus and skin. J Pathol. 2010; 220(4):446-451.

51. Shibata T, Kokubu A, Saito S, et al. NRF2 mutation confers malignant potential and resistance to chemoradiation therapy in advanced esophageal squamous cancer. Neoplasia. 2011;13(9):864-873. 
52. Wang R, An J, Ji F, et al. Hypermethylation of the Keap1 gene in human lung cancer cell lines and lung cancer tissues. Biochem Biophys Res Commun. 2008;373(1):151-154.

53. Hanada N, Takahata T, Zhou Q, et al. Methylation of the KEAP1 gene promoter region in human colorectal cancer. BMC Cancer. 2012; 12(1):66.

54. Ichimura Y, Waguri S, Sou YS, et al. Phosphorylation of p62 Activates the Keap1-Nrf2 Pathway during Selective Autophagy. Mol Cell. 2013;51(5):618-631

55. Inami $\mathrm{Y}$, Waguri $\mathrm{S}$, Sakamoto A, et al. Persistent activation of Nrf2 through p62 in hepatocellular carcinoma cells. J Cell Biol. 2011; 193(2):275-284.

56. Ooi A, Wong J-C, Petillo D, et al. An antioxidant response phenotype shared between hereditary and sporadic type 2 papillary renal cell carcinoma. Cancer Cell. 2011;20(4):511-523.

57. He X, Ma Q. NRF2 cysteine residues are critical for oxidant/ electrophile-sensing, Kelch-Like ECH-associated protein-1-dependent ubiquitination-proteasomal degradation, and transcription activation. Mol Pharmacol. 2009;76(6):1265-1278.

58. Wilson AJ, Kerns JK, Callahan JF, Moody CJ. Keap Calm, and Carry on Covalently. J Med Chem. 2013;56(19):7463-7476.

59. Abed DA, Goldstein M, Albanyan H, et al. Discovery of direct inhibitors of Keap1-Nrf2 protein-protein interaction as potential therapeutic and preventive agents. Acta Pharm Sin B. 2015;5(4):285-299.

60. Chen Y, Inoyama D, Kong A-NT, et al. Kinetic analyses of Keap1-Nrf2 interaction and determination of the minimal Nrf2 peptide sequence required for Keap1 binding using surface plasmon resonance. Chem Biol Drug Des. 2011;78(6):1014-1021.

61. Inoyama D, Chen Y, Huang X, et al. Optimization of fluorescently labeled Nrf2 peptide probes and the development of a fluorescence polarization assay for the discovery of inhibitors of Keap1-Nrf2 interaction. J Biomol Screen. 2012;17(4):435-447.

62. Zhuang C, Miao Z, Sheng C, et al. Updated research and applications of small molecule inhibitors of Keap1-Nrf2 protein-protein interaction: a review. Curr Med Chem. 2014;21(16):1861-1870.

63. Hancock R, Bertrand HC, Tsujita T, et al. Peptide inhibitors of the Keap1-Nrf2 protein-protein interaction. Free Radic Biol Med. 2012;52(2):444-451.

64. Hancock R1, Schaap M, Pfister H, Wells G. Peptide inhibitors of the Keap1-Nrf2 protein-protein interaction with improved binding and cellular activity. Org Biomol Chem. 2013;11(21):3553-3557.

65. Steel R, Cowan J, Payerne E, et al. Anti-inflammatory effect of a cellpenetrating peptide targeting the Nrf2/Keap1 interaction. ACS Med Chem Lett. 2012;3(5):407-410.

66. Hu L, Magesh S, Chen L, et al. Discovery of a small-molecule inhibitor and cellular probe of Keap1-Nrf2 protein-protein interaction. Bioorg Med Chem Lett. 2013;23(10):3039-3043.

67. Marcotte D, Zeng W, Hus J-C, et al. Small molecules inhibit the interaction of Nrf2 and the Keap1 Kelch domain through a non-covalent mechanism. Bioorg Med Chem. 2013;21(14):4011-4019.

68. Singh A, Venkannagari S, Oh KH, et al. Small molecule inhibitor of NRF2 selectively intervenes therapeutic resistance in KEAP1-deficient NSCLC tumors. ACS Chem Biol. 2016;11(11):3214-3225.

69. Bollong MJ, Yun H, Sherwood L, et al. A small molecule inhibits deregulated NRF2 transcriptional activity in cancer. ACS Chem Biol. 2015;10(10):2193-2198.

70. Sun H-P, Jiang Z-Y, Zhang M-Y, et al. Novel protein-protein interaction inhibitor of Nrf2-Keap1 discovered by structure-based virtual screening. Med Chem Commun. 2014;5(1):93-98.

71. Zhuang C, Narayanapillai S, Zhang W, et al. Rapid Identification of Keap1-Nrf2 Small-Molecule Inhibitors through Structure-Based Virtual Screening and Hit-Based Substructure Search. J Med Chem. 2014;57(3):1121-1126.

72. Satoh M, Saburi H, Tanaka T, et al. Multiple binding modes of a small molecule to human Keap1 revealed by X-ray crystallography and molecular dynamics simulation. FEBS Open Bio. 2015;5(1): $557-570$.
73. Bertrand HC, Schaap M, Baird L, et al. Design, synthesis, and evaluation of triazole derivatives that induce Nrf2 dependent gene products and inhibit the Keap1-Nrf2 protein-protein interaction. $J$ Med Chem. 2015;58(18):7186-7194.

74. Davies TG, Wixted WE, Coyle JE, et al. Monoacidic Inhibitors of the Kelch-like ECH-Associated Protein 1: Nuclear factor erythroid 2-related factor 2 (KEAP1:NRF2) protein-protein interaction with high cell potency identified by fragment-based discovery. J Med Chem. 2016;59(8):3991-4006.

75. Zhong M, Lynch A, Jehle S, et al. Fragment-based drug discovery targeting KEAP1/Nrf2 binding. Faseb J. 2015;29(1_Suppl):Abstract 712.20.

76. Fosgerau K, Hoffmann T. Peptide therapeutics: current status and future directions. Drug Discov Today. 2015;20(1):122-128.

77. Jnoff E, Albrecht C, Barker JJ, et al. Binding mode and structure-activity relationships around direct inhibitors of the Nrf2-Keap1 complex. ChemMedChem. 2014;9(4):699-705.

78. Jiang ZY, Lu MC, Xu LL, et al. Discovery of potent Keap1-Nrf2 protein-protein interaction inhibitor based on molecular binding determinants analysis. J Med Chem. 2014;57(6):2736-2745.

79. Jiang ZY, Xu LL, Lu MC, et al. Structure-activity and structureproperty relationship and exploratory in vivo evaluation of the nanomolar Keap1-Nrf2 protein-protein interaction inhibitor. $J$ Med Chem. 2015;58(16):6410-6421.

80. Li X, Zhang D, Hannink M, Beamer LJ. Crystal structure of the Kelch domain of human Keap1. Journal of Biological Chemistry. 2004;279(52):54750-54758.

81. Jain $\mathrm{AD}$, Potteti H, Richardson BG, et al. Probing the structural requirements of non-electrophilic naphthalene-based Nrf2 activators. Eur $J$ Med Chem. 2015;103:252-268.

82. Saito T, Ichimura Y, Taguchi K, et al. p62/Sqstm1 promotes malignancy of HCV-positive hepatocellular carcinoma through Nrf2-dependent metabolic reprogramming. Nat Commun. 2016;7:12030.

83. Winkel AF, Engel CK, Margerie D, et al. Characterization of RA839, a noncovalent small molecule binder to Keap1 and selective activator of Nrf2 signaling. J Biol Chem. 2015;290(47):28446-28455.

84. Wahle KWJ, Brown I, Rotondo D, Heys SD. Plant phenolics in the prevention and treatment of cancer. Adv Exp Med Biol. 2010;698:36-51.

85. Huang MT, Ferraro T. Phenolic compounds in food and cancer prevention. In: Huang MT, Ho CT, Lee CY, editors. Phenolic Compounds in Food and their Effects on Health II: Antioxidants and Cancer Prevention. Washington, DC: American Chemical Society; 1992:8-34.

86. Hatcher H, Planalp R, Cho J, et al. Curcumin: From ancient medicine to current clinical trials. Cell Mol Life Sci. 2008;65(11):1631-1652.

87. Whitlock NC, Baek SJ. The anticancer effects of resveratrol: Modulation of transcription factors. Nutr Cancer. 2012;64(4):493-502.

88. Rauf A, Imran M, Butt MS, et al. Resveratrol as an anti-cancer agent: A review. Crit Rev Food Sci Nutr. 2018;58(9):1428-1447.

89. Kunnumakkara AB, Anand P, Aggarwal BB. Curcumin inhibits proliferation, invasion, angiogenesis and metastasis of different cancers through interaction with multiple cell signaling proteins. Cancer Lett. 2008;269(2):199-225.

90. Chen B, Zhang Y, Wang Y, et al. Curcumin inhibits proliferation of breast cancer cells through Nrf2-mediated down-regulation of Fen1 expression. J Steroid Biochem Mol Biol. 2014;143:11-18.

91. Adiwidjaja J, Mclachlan AJ, Boddy AV. Curcumin as a clinicallypromising anti-cancer agent: pharmacokinetics and drug interactions. Expert Opin Drug Metab Toxicol. 2017;13(9):953-972.

92. Burgos-Morón E, Calderón-Montaño JM, Salvador J, Robles A, LópezLázaro M. The dark side of curcumin. Int J Cancer. 2010;126(7): 1771-1775.

93. National Toxicology Program. NTP toxicology and carcinogenesis studies of turmeric oleoresin (CAS No. 8024-37-1) (Major component 79\%-85\% curcumin, CAS No. 458-37-7) in F344/N rats and B6C3F1 mice (Feed studies). Natl Toxicol Program Tech Rep Ser. 1993;427:1-275.

94. Singh B, Shoulson R, Chatterjee A, et al. Resveratrol inhibits estrogeninduced breast carcinogenesis through induction of NRF2-mediated protective pathways. Carcinogenesis. 2014;35(8):1872-1880. 
95. Li C, Xu X, Wang XJ, Pan Y. Imine resveratrol analogues: Molecular design, Nrf2 activation and SAR analysis. PLoS One. 2014;9(7): e101455.

96. Chen C, Yu R, Owuor ED, et al. Activation of antioxidant-response element (ARE), mitogen-activated protein kinases (MAPKs) and caspases by major green tea polyphenol components during cell survival and death. Arch Pharm Res. 2000;23(6):605-612.

97. Houghton CA, Fassett RG, Coombes JS. Sulforaphane and other nutrigenomic Nrf2 activators: Can the clinician's expectation be matched by the reality? Oxid Med Cell Longev. 2016;2016(1, supplement):7857186-17.

98. Hanlon N, Coldham N, Gielbert A, et al. Absolute bioavailability and dose-dependent pharmacokinetic behaviour of dietary doses of the chemopreventive isothiocyanate sulforaphane in rat. Br J Nutr. 2008; 99(03):559-564.

99. Riedl MA, Saxon A, Diaz-Sanchez D. Oral sulforaphane increases Phase II antioxidant enzymes in the human upper airway. Clin Immunol. 2009;130(3):244-251.

100. Ye L, Dinkova-Kostova AT, Wade KL, et al. Quantitative determination of dithiocarbamates in human plasma, serum, erythrocytes and urine: pharmacokinetics of broccoli sprout isothiocyanates in humans. Clin Chim Acta. 2002;316(1-2):43-53.

101. Cornblatt BS, Ye L, Dinkova-Kostova AT, et al. Preclinical and clinical evaluation of sulforaphane for chemoprevention in the breast. Carcinogenesis. 2007;28(7):1485-1490.

102. Dinkova-Kostova AT, Fahey JW, Kostov RV, Kensler TW. KEAP1 and done? Targeting the NRF2 pathway with sulforaphane. Trends Food Sci Technol. 2017;69(Pt B):257-269.

103. Russo M, Spagnuolo C, Russo GL, et al. Nrf2 targeting by sulforaphane: A potential therapy for cancer treatment. Crit Rev Food Sci Nutr. 2018;58(8):1391-1405.

104. Sun H, Zhu J, Lin H, Gu K, Feng F. Recent progress in the development of small molecule Nrf2 modulators: a patent review (2012-2016). Expert Opin Ther Pat. 2017;27(7):763-785.

105. Wang YY, Yang YX, Zhe H, He ZX, Zhou SF. Bardoxolone methyl (CDDO-Me) as a therapeutic agent: an update on its pharmacokinetic and pharmacodynamic properties. Drug Des Devel Ther. 2014;8: 2075-2088.

106. Hong DS, Kurzrock R, Supko JG, et al. A phase I first-in-human trial of bardoxolone methyl in patients with advanced solid tumors and lymphomas. Clin Cancer Res. 2012;18(12):3396-3406.

107. Creelan BC, Gabrilovich DI, Gray JE, et al. Safety, pharmacokinetics, and pharmacodynamics of oral omaveloxolone (RTA 408), a synthetic triterpenoid, in a first-in-human trial of patients with advanced solid tumors. Onco Targets Ther. 2017;10:4239-4250.

108. Patel SP, Hodi FS, Gabrilovich D, et al. 5O_PRA phase 1b/2 study of omaveloxolone in combination with checkpoint inhibitors in patients with unresectable or metastatic melanoma. Ann Oncol. 2017; 28(suppl_11)mdx760.

109. Benarroch EE. Nrf2, cellular redox regulation, and neurologic implications. Neurology. 2017;88(20):1942-1950.

110. Tu ZS, Wang Q, Sun DD, Dai F, Zhou B. Design, synthesis, and evaluation of curcumin derivatives as Nrf2 activators and cytoprotectors against oxidative death. Eur J Med Chem. 2017;134:72-85.

111. Vyas A, Dandawate P, Padhye S, Ahmad A, Sarkar F. Perspectives on new synthetic curcumin analogs and their potential anticancer properties. Curr Pharm Des. 2013;19(11):2047-2069.

112. Kachadourian R, Day BJ, Pugazhenti S, et al. A synthetic chalcone as a potent inducer of glutathione biosynthesis. J Med Chem. 2012; 55(3):1382-1388.

113. Gold R, Kappos L, Arnold DL, et al. Placebo-controlled phase 3 study of oral BG-12 for relapsing multiple sclerosis. $N$ Engl J Med. 2012;367(12):1098-1107.

114. Linker RA, Haghikia A. Dimethyl fumarate in multiple sclerosis: latest developments, evidence and place in therapy. Ther Adv Chronic Dis. 2016;7(4):198-207.
115. Saidu NE, Noé G, Cerles O, et al. Dimethyl fumarate controls the NRF2/DJ-1 axis in cancer cells: Therapeutic applications. Mol Cancer Ther. 2017;16(3):529-539.

116. Bennett Saidu NE, Bretagne M, Mansuet AL, et al. Dimethyl fumarate is highly cytotoxic in KRAS mutated cancer cells but spares nontumorigenic cells. Oncotarget. 2018;9(10):9088-9099.

117. Loewe R, Valero T, Kremling S, et al. Dimethyl fumarate impairs melanoma growth and metastasis. Cancer Res. 2006;66(24):11888-11896.

118. Xi MY, Jia JM, Sun HP, et al. 3-aroylmethylene-2,3,6,7-tetrahydro1H-pyrazino[2,1-a]isoquinolin-4(11bH)-ones as potent $\mathrm{Nrf2/ARE}$ inducers in human cancer cells and AOM-DSS treated mice. $J$ Med Chem. 2013;56(20):7925-7938.

119. Childers WE, Abou-Gharbia M, Biswal S, Thimmulappa RK, inventors; Cureveda, LLC, assignee. Functionalized heteroaryl enones exhibiting Nrf2 activation and their method of use. United States patent US WO2015187934A1. Cureveda, Llc. 2015 Dec 10.

120. You Q, Yang T, Sun Y, et al, inventors; China Pharmaceutical University, assignee. Pyridopyrazine compounds as Nrf2 activators and their preparation, pharmaceutical compositions and use in the treatment of inflammation and cancer. Chinese patent CN105566323A. 2016 May 11.

121. Harder B, Tian W, La Clair JJ, et al. Brusatol overcomes chemoresistance through inhibition of protein translation. Mol Carcinog. 2017;56(5):1493-1500.

122. Zhu J, Wang H, Chen F, et al. An overview of chemical inhibitors of the Nrf2-ARE signaling pathway and their potential applications in cancer therapy. Free Radic Biol Med. 2016;99:544-556.

123. Ren D, Villeneuve NF, Jiang T, et al. Brusatol enhances the efficacy of chemotherapy by inhibiting the Nrf2-mediated defense mechanism. Proc Natl Acad Sci U S A. 2011;108(4):1433-1438.

124. Jaramillo MC, Zhang DD. The emerging role of the Nrf2-Keap1 signaling pathway in cancer. Genes Dev. 2013;27(20):2179-2191.

125. Vartanian S, Ma TP, Lee J, et al. Application of mass spectrometry profiling to establish brusatol as an inhibitor of global protein synthesis. Mol Cell Proteomics. 2016;15(4):1220-1231.

126. Harder B, Tian W, La Clair JJ, et al. Brusatol overcomes chemoresistance through inhibition of protein translation. Mol Carcinog. 2017;56(5):1493-1500.

127. Hall IH, Lee KH, Eigebaly SA, et al. Antitumor agents. XXXIV: Mechanism of action of bruceoside $A$ and brusatol on nucleic acid metabolism of P-388 lymphocytic leukemia cells. J Pharm Sci. 1979; 68(7):883-887.

128. Ren D, Villeneuve NF, Jiang T, et al. Brusatol enhances the efficacy of chemotherapy by inhibiting the Nrf2-mediated defense mechanism. Proc Natl Acad Sci U S A. 2011;108(4):1433-1438.

129. Tang W, Xie J, Xu S, et al. Novel nitric oxide-releasing derivatives of brusatol as anti-inflammatory agents: design, synthesis, biological evaluation, and nitric oxide release studies. J Med Chem. 2014;57(18): 7600-7612.

130. Tang X, Wang H, Fan L, et al. Luteolin inhibits Nrf2 leading to negative regulation of the Nrf2/ARE pathway and sensitization of human lung carcinoma A549 cells to therapeutic drugs. Free Radic Biol Med. 2011; 50(11):1599-1609.

131. Gao AM, Ke ZP, Wang JN, et al. Apigenin sensitizes doxorubicinresistant hepatocellular carcinoma BEL-7402/ADM cells to doxorubicin via inhibiting PI3K/Akt/Nrf2 pathway. Carcinogenesis. 2013; 34(8):1806-1814.

132. Gao AM, Ke ZP, Shi F, Sun GC, Chen H. Chrysin enhances sensitivity of BEL-7402/ADM cells to doxorubicin by suppressing PI3K/Akt/Nrf2 and ERK/Nrf2 pathway. Chem Biol Interact. 2013;206(1):100-108.

133. Liao JC, Lee KT, You BJ, et al. Raf/ERK/Nrf2 signaling pathway and MMP-7 expression involvement in the trigonelline-mediated inhibition of hepatocarcinoma cell migration. Food Nutr Res. 2015;59:29884.

134. Broekgaarden M, Weijer R, van Gulik TM, Hamblin MR, Heger M. Tumor cell survival pathways activated by photodynamic therapy: a molecular basis for pharmacological inhibition strategies. Cancer Metastasis Rev. 2015;34(4):643-690. 
135. Arlt A, Sebens S, Krebs S, et al. Inhibition of the Nrf2 transcription factor by the alkaloid trigonelline renders pancreatic cancer cells more susceptible to apoptosis through decreased proteasomal gene expression and proteasome activity. Oncogene. 2013;32(40):4825-4835.

136. Tsuchida K, Tsujita T, Hayashi M, et al. Halofuginone enhances the chemo-sensitivity of cancer cells by suppressing NRF2 accumulation. Free Radic Biol Med. 2017;103:236-247.

137. Pines M, Spector I. Halofuginone - the multifaceted molecule. Molecules. 2015;20(1):573-594.

138. Biswal SS, Singh A, Rastinejad F, et al, inventors; National Institutes of Health (NIH), Johns Hopkins University, Sanford-Burnham Prebys Medical Discovery Institute, assignee. Nrf2 small molecule inhibitors for cancer therapy. United States patent US20160046616A1. 2016 Feb 18 .
139. Liu $\mathrm{X}$, Zhu Q, Zhang M, et al. Isoliquiritigenin ameliorates acute pancreatitis in mice via inhibition of oxidative stress and modulation of the Nrf2/HO-1 pathway. Oxid Med Cell Longev. 2018;2018:Article 7161592.

140. Choi EJ, Jung BJ, Lee SH, et al. A clinical drug library screen identifies clobetasol propionate as an NRF2 inhibitor with potential therapeutic efficacy in KEAP1 mutant lung cancer. Oncogene. 2017;36(37):5285-5295.

141. Duong HQ, Yi YW, Kang HJ, et al. Inhibition of NRF2 by PIK-75 augments sensitivity of pancreatic cancer cells to gemcitabine. Int $J$ Oncol. 2014;44(3):959-969.

\section{Publish your work in this journal}

Drug Design, Development and Therapy is an international, peerreviewed open-access journal that spans the spectrum of drug design and development through to clinical applications. Clinical outcomes, patient safety, and programs for the development and effective, safe, and sustained use of medicines are the features of the journal, which has also been accepted for indexing on PubMed Central. The manuscript management system is completely online and includes a very quick and fair peer-review system, which is all easy to use. Visit http://www.dovepress.com/testimonials.php to read real quotes from published authors.

Submit your manuscript here: http://www.dovepress.com/drug-design-development-and-therapy-journal 